Revista de Estudios Histórico-Jurídicos

[Sección Derecho Romano]

XXXV (Valparaíso, Chile, 2013)

[pp. 81 - 110]

\title{
El TRINOMIO "POTESTAS MANUS MANCIPIUMQUE" [Trinomial "Potestas Manus Manicipiumque"]
}

\author{
Carlos Amunátegui Perelló* \\ Pontifica Universidad Católica de Chile, Santiago de Chile
}

\begin{abstract}
RESUMEN
En este artículo analizamos los orígenes del conocido trinomio "potestas manus mancipioque" que define el conjunto de los poderes del paterfamilias en la obra de Gayo. Partiendo del análisis de este sintagma retrotraemos su origen a la etapa arcaica de la Historia de Roma y lo relacionamos con los diversos mecanismos de control de bienes con que se cuenta en dicho período.

$$
\begin{gathered}
\text { Palabras Clave } \\
\text { Potestas - Manus - Mancipium - Pro- }
\end{gathered}
$$$$
\text { piedad - Roma arcaica. }
$$

\begin{abstract}
In this article we analyze the origins of well-known trinomial "potestasmanusmancipioque", which defines the set of the paterfamilias powers in the work of Gayo. Starting with the analysis of this phrase we carry back its origins to the ancient stages of the History of Rome and related it with the several mechanisms to control the properties of that period.

KeYwordS

Potestas - Manus - Mancipium - Property - Ancient Rome.
\end{abstract}

RECiBIDO el 30 de abril de 2013 y ACEPTADO el 2 de mayo de 2013.

* Profesor de Derecho romano de la Pontificia Universidad Católica de Chile. Dirección postal: Facultad de Derecho, Pontificia Universidad Católica de Chile, Avenida Bernardo O’Higgins 340, Santiago, Chile. Correo electrónico: camunate@uc.cl Este artículo es parte del proyecto de investigación Fondecyt regular No 1100452. 


\section{INTRODUCCIÓN Y TEORÍAS}

Gayo comienza sus Institutiones analizando las personas, para lo cual realiza dos grandes clasificaciones que le orientarán en el desarrollo de la materia. Primero nos señala que todos los hombres pueden ser libres o siervos ${ }^{1}$, para luego, un poco más adelante, indicar que las personas pueden ser independientes (sui iuris) o estar bajo el derecho ajeno ("alieno iuri subiectae") ${ }^{2}$. Al respecto Gayo dice que, de entre quienes están bajo el derecho ajeno, algunos están bajo manus, otros bajo potestas y otros en mancipio. El texto es Gai. 1,49: "Sed rursus earum personarum, quae alieno iuri subiectae sunt, aliae in potestate, aliae in manu, aliae in mancipio sunt".

Así, bajo la potestas se encontrarían tanto los hijos de familia ${ }^{3}$ como los escla$\operatorname{vos}^{4}$, mientras que sujetos a los otros dos poderes estarían solamente a la mujer que ha realizado conventio in manum ${ }^{5}$ y al hijo mancipado por su padre ${ }^{6}$. En base a esta tripartición de los poderes del paterfamilias será que Gayo desarrolle su libro primero sobre las personas y, a continuación, en los tres libros restantes sobre las cosas y las acciones, trate las materias que se relacionen con ellos ${ }^{7}$, por lo que podemos concluir que esta clasificación tiene la mayor imortancia dentro de la sistemática de la obra de Gayo. Dicha información nos resulta fundamental, puesto que nos insinúa un esquema relativo a los poderes del paterfamilias no sólo respecto a las personas, sino también sobre las cosas, toda vez que la potestas sobre los esclavos queda subsumida dentro del dominium, mientras que la potestas que recae sobre los hijos de familia nunca se intenta equiparar al dominio. En cuanto a la posición de las mujeres que han entrado en la manus ésta se asimila a la de los hijos utilizando el sintagma "loco filiae" para describirla ${ }^{8}$, mientras que

${ }^{1}$ Gai. 1,9 [III. De CONDICIONE HOMINUM] Et quidem summa diuisio de iure personarum haec est, quod omnes homines aut liberi sunt aut serui.

${ }^{2}$ Gai. 1,48: "Sequitur de iure personarum alia diuisio. nam quaedam personae sui iuris sunt, quaedam alieno iuri sunt subiectae".

${ }^{3}$ Gai. 1,55: "Item in potestate nostra sunt liberi nostri, quos iustis nuptiis procreauimus. quod ius proprium ciuium Romanorum est...”.

${ }^{4}$ Gai. 1.52: "In potestate itaque sunt serui dominorum. quae quidem potestas iuris gentium est: nam apud omnes peraeque gentes animaduertere possumus dominis in seruos uitae necisque potestatem esse, et quodcumque per seruum adquiritur, id domino adquiritur".

${ }^{5}$ Gai. 1.108: "<Nunc de his personis uideamus, quae in manu nostra sunt. quod > et ipsum ius proprium ciuium Romanorum est. 1.109 Sed in potestate quidem et masculi et feminae esse solent; in manum autem feminae tantum conueniunt".

${ }^{6}$ Gai. 1.117: "Omnes igitur liberorum personae, siue masculini siue feminini sexus, quae in potestate pa-rentis sunt, mancipari ab hoc eodem modo possunt, quo etiam serui mancipari possunt".

${ }^{7} \mathrm{Al}$ respecto, véanse: Amunátegui Perelló, Carlos, "Loco filiae", en Carvajal, Patricio (editor), Homenaje al profesor Francisco Samper Polo (Santiago, Librotecnia, 2007), pp. 45-66; y El Mismo, Origen de los poderes del "paterfamilias" (Madrid, Dykinson, 2009), pp. 341-366.

${ }^{8}$ Gai. 1,$111 ; 1,114 ; 1,115$ b; 1,118; 1,136; 2,139; 2,159; 3,3. En el Epitome Gai también se utiliza en 1,5,2. También se encuentra utilizada, posiblemente por influencia del mismo Gayo, en el tardío comentarista Servio, In Georg. 1,31,6: "coemptione vero atque in manum conventione, cum illa in filiae locum, maritus in patris veniebat, ut siquis prior fuisset defunctus, locum hereditatis iustum alteri faceret"; y en SEN. mai., Contr. 9,5,15,9: "Non fuit contentus; adiecit: in paternis tabulis filiae locus aut suus debetur aut nullus". 
los hijos mancipados se encuentran en una situación equiparable a los esclavos, en el sentido que se dice que están "servorum loco".

No obstante, no podemos estar seguros acerca de la época en que esta clasificación quedó cristalizada dentro del Derecho romano, ni menos de la antigüedad de la misma, toda vez que la obra de Gayo, al pertenecer al principado, nos da simplemente una fecha ante quam donde debemos estimarla consolidada. Tal tripartición ha dado bastante que pensar a la romanística, toda vez que a través de ella se vislumbra el conjunto de poderes que habría ostentado el paterfamilias sobre personas y cosas, de manera que los autores que han pretendido encontrar una interpretación de los poderes del paterfamilias han debido, en más de una oportunidad, referirse a ella. Esto fue importante tanto para los autores que se centraron en una visión soberanista de la patria potestas ${ }^{10}$, intentando trazar a partir de ella el desarrollo del Estado, como también quienes trazaron teorías rivales que buscaban realizar la misma construcción, pero desde la propiedad ${ }^{11}$, lo cual ha terminó por convertir el sencillo sintagma en un verdadero campo de batalla para las ideologías del siglo XIX y comienzos del XX.

A fin de ordenar las posiciones doctrinarias, podemos comenzar por aquéllas que tienden a estimar que la tripartición gayana era, en algún tiempo remoto generalmente coincidente con la fundación de la ciudad, originalmente un solo poder que asumía alguno de los tres nombres entregados por el jurista. En efecto, parte de la doctrina de principios del siglo XX consideraba que originariamente, esto es, en época pre-etrusca, el paterfamilias ostentaba simplemente un poder, llamado "manus" 12 según algunos o "mancipium"13 de conformidad a otros, que se

\footnotetext{
${ }^{9}$ Gai. 1,138: "Ii, qui in causa mancipii sunt, quia seruorum loco habentur, uindicta, censu, testamento manumissi sui iuris funt".

${ }^{10}$ En este sentido Arangio-Ruiz, Vincenzo, Le genti e le città (Messina, D’Angelo, 1914), seguido por VocI, Pascuale, Esame delle tesi del Bonfante su la famiglia romana arcaica, en Studi in onore di Arangio-Ruiz (Napoli, Jovene, 1953), I, p. 101; KASER, Max, La famiglia romana arcaica, en Conferenze romanistiche (Milano, Giuffré, 1960); y PugliesE, Giovanni, Aperçu historique de la famille romaine, ahora en Scritti giuridici scelti (Napoli, Jovene, 1985), III, p. 11.

${ }^{11}$ Véanse: De VIsCHER, Fernand, "Mancipium” et "res mancipi", en SDHI. 2 (1936), p. 213 ss.; Bonfante, Pietro, Corso di Diritto romano, I: Diritto di famiglia (Milano, Giuffrè, 1963), p. 7; El MISMO, La gens e la familia, en El MISMO, Scritti giuridici. Famiglia e successione (Torino, Unione Tipografica Editrice Torinese, 1916); aceptando también parcialmente la teoría política: De Martino, Francesco, La "gens", lo Stato e le classi in Roma antica, en Studi in onore di V. Arangio-Ruiz (Napoli, Jovene, 1953), IV, p. 25.

${ }^{12}$ Volgt, Moritz, Römisches Rechtgechichte (Leipzig, Liebeskind, 1892), I, p. 348; BONFanTE, Pietro, Corso di diritto romano. La proprietà (Milano, Giuffrè, 1966), II,1, p. 230; LeIFer, Franz, "Mancipium" und "auctoritas", en ZSS., rom. Abt., 56 (1936), p. 154; KASER, Max Der römische Eigentumsbegriff, en El MISMO, Ausgewählte Schriften (Napoli, Jovene, 1976), II, p. 52; CASINOS MORA, Francisco Javier, La noción romana de "auctoritas" y la responsabilidad por "auctoritas" (Granada, 2000), p. 77; FuenteseCA DegenefFe, Margarita, La formación romana del concepto de propiedad (Madrid, Dykinson, 2004), pp. 26-135; CoRnIL, Georges, Du "mancipium" au "dominium", en Festschrift Paul Koschaker zum 60 Geburstag (Weimar, Böhlau, 1939), I, pp. 404-443. Sin embargo, éste último precisa que el poder sobre las cosas que directamente colaboran en el culto doméstico (es decir, hijos y mujer) se denominaría manus, mientras que el poder sobre los colaboradores indirectos (clientes, aedes, fundi, domita animalia), se denominaría mancipium.
}

${ }^{13}$ De Visscher, F., “Mancipium”, cit. (n. 11), p. 227; DıósdI, György, Ownership in Ancient 
ejercía sobre cosas y personas indistintamente. Sin embargo, producto de la dominación etrusca ${ }^{14} \mathrm{o}$, más tardíamente, del surgimiento del concepto de propiedad, es que se habría introducido la potestas y, con ella, un poder más individualista y absoluto que terminó en generar esta tripartición.

Otros se muestran escépticos ante esta posibilidad ${ }^{15}$, y postulan ${ }^{16}$ el sintagma apunta a que originariamente los poderes del paterfamilias habrían sido descritos sólo analíticamente y no existiría un poder onmicomprensivo del cual derivasen los demás. Así, ciertos poderes del trinomio (potestas y manus) se refirirían sólo a personas, mientras que el tercer elemento (mancipium) apuntaría a la pertenencia de las $\operatorname{cosas}^{17}$, el cual sería paulatinamente sustituído por el dominium según el concepto se desarrollase en el siglo I a. C. ${ }^{18}$

Sin embargo, todas estas posiciones se fundamentan en la antigüedad de la expresión "potestas manus mancipioque" que encontramos en Gayo, y esta cuestión que ha sido criticada fuertemente a contar de la década del sesenta ${ }^{19}$. En efecto, hasta entonces se encontraba incólumne la autoridad de Mommsen en cuanto a la inclusión de dicho sintagma en la lex Cincia, lo cual garantizaba la antigüedad de la expresión, al menos remontándola a un tiempo anterior a la creación de la jurisprudencia laica y, por tanto, ubicándola dentro del saber pontifical tradicional. Sin embargo, Casavola, a comienzos de los sesenta, realizó un trabajo bastante persuasivo en que ponía en crisis la interpretación mommseniana del correspondiente parágrafo de la lex Cincia, demostrando que se trataba de una interpretación ideológica de la notación manuscrita aparecida en los Fragmenta Vaticana, y especialmente en el manuscrito Vaticanus 5766, que parece decir

and Preclassical Roman Law (Budapest, Akadémiai Kiadó, 1970), p. 54; Albanese, Bernardo, "Cum nexum faciet mancipiumque", ahora en Brevi studi di Diritto romano (Palermo, Palumbo, 1992), p. 60; PUGLIESE, Giovanni, "Res corporales" e "res incoporales", ahora en Scritti giuridici scelti (Jovene, Napoli, 1985), III, pp. 252; PACHECO CABALlERO, Francisco, Las servidumbres prediales en el Derecho histórico español (Lleida, Pagés, 1991), p. 20; LozAno CorBI, Enrique, Origen de la propiedad romana y de sus limitaciones, en Estudios de Derecho romano en memoria de Benito María Reimundo Yanes (Burgos, Universidad de Burgos, 2000), I, p. 573; SERraO, Feliciano, Diritto privato economia e società nella storia di Roma (Napoli, Jovene, 2006), I, pp. 196.

${ }^{14}$ Cornil, G., Du “mancipium”, cit. (n. 12), p. 413.

${ }^{15}$ Watson, Allan, Rome of the XII Tables (New Jersey, Princeton University Press, 1975), p. 134.

${ }^{16}$ Franciosi, Gennaro, Famiglia e persone in Roma antica (Torino, Giappichelli, 1992), p. 46.

${ }^{17}$ Kretschmar, Paul, Das "nexum" und sein Verhältnis zum "mancipium”, en ZSS., rom. Abt., 29 (1908) p. 235.

${ }^{18}$ CAPOgrossi Colognesi, Luigi, La struttura della proprietà e la formazione dei iura praediorum nell eta republicana (Milano, Giuffrè, 1969), I, pp. 464-465; Franciosi, G., Famiglia , cit. (n. 16), p. 44.

${ }^{19}$ En esta línea: Casavola, Franco, "Lex Cincia". Contributo alla storia delle origini della donazione romana (Napoli, Università di Napoli, 1960), pp. 58-60; MEYLAN, Philippe, Origine de la formule "in potestate manu mancipioque", en Etudes offertes à Jean Macqueron (Aix-enProvence, Faculté de Droit Aix-en-Provence, 1970), pp. 503-513; CaPogrossi Colognesi, L., Struttura, cit. (n. 18), I, p. 151; BRETONE, Mario, La nozione romana di usufrutto (Napoli, Jovene, 1962), p. 22 n. 4. 
más bien "potestas manus matrimoniove". Hoy por hoy, la doctrina especializada, especialmente por la autoridad de Cappogrossi, tiende a creer que el sintagma "potestas manus mancipioque" es una creación del siglo II, propia del vocabulario expositivo de $\mathrm{Gayo}^{20}$. Este aspecto ha dado cierta incerteza a la época en que la distinción fue sintetizada y, por tanto, al conjunto de poderes que habría ejercido el paterfamilias en época Arcaica. A través de este trabajo pretendemos volver sobre el sintagma "potestas manus mancipioque" intentando un análisis del mismo en sus aspectos textuales, para luego volver sobre el problema de la tripartición de los poderes del paterfamilias sobre los distintos sujetos que se encuentran bajo su dependencia.

\section{EXAMEN DE LOS TEXTOS}

La tripartición de los poderes del paterfamilias aparece mencionada no sólo en los textos de Gayo ya citados, sino también en la lex Salpensanum. Se trata de una ley dictada en época de Domiciano, entre los años 81 y 84 de nuestra Era que fija el estatus de municipio de la ciudad ${ }^{21}$, hallada en una tabla de bronce en 1851 en Málaga. De conformidad a la misma, en su capítulo XXII se establecee ${ }^{22}$ : "Qui quaeque ex h. l. exve edicto imp(eratoris) Caesaris Aug(usti) Vespasiani, imp(eratoris) ve Titi | Caesaris Aug(usti), aut imp(eratoris) Caesaris Aug(usti) Domitiani p(atris) $p$ (atriae), civitatem Roman (am) | consecutus consecuta erit : is ea in eius, qui c(ivis) $R$ (omanus) $h$ (ac) l(ege) factus erit, potestate | manu mancipio, cuius esse deberet, si civitate Romana mutatus | mutata non esset, esto idque ius tutoris optandi habeto, quod | haberet, si a cive Romano ortus orta neq(ue) civitate mutatus mu|tata esset".

La norma intenta simplemente conservar el status familiae de quienes adquieren la ciudadanía romana, de manera que, si eran alieno iure subiectos, permanezcan en la misma posición en que se encontraban antes de su adquisición de la ciudadanía, lo cual se describe analíticamente ${ }^{23}$ como "potestate manu mancipio". Varias cosas resultan interesantes de este precepto, toda vez que la veracidad del texto no puede ser cuestionada ${ }^{24}$. En primer término, la fórmula aparece estereotipada ${ }^{25}$, como una manera de describir la posición de quienes se encuentran bajo la dependencia ajena utilizando una nominación cumulativa de facultades. Sin embargo, no se hace uso de la más sintética expresión "alieno iuris subiectae", que habría hecho suponer la existencia de una teorización general sobre la posición subordinada

${ }^{20}$ Capogrossi Colognesi, L., Struttura, cit. (n. 18), I, p. 253; MeYlan, Ph., Origine, cit. (n. 19), p. 513.

${ }^{21} \mathrm{Al}$ respecto de la política de los Flavios y la romanización de Hispania, un tratamiento interesante y actualizado en Bravo Bosch, María José, El largo camino de los "hispani” hacia la ciudadania (Madrid, Dykinson, 2008), pp. 185-230.

${ }^{22}$ Girard, Paul Frédéric - Senn, Félix, Les lois des Romains (Napoli, Jovene, 1977), pp. 40-41.

${ }^{23}$ Franciosi, G., Famiglia, cit. (n. 16), p. 46.

${ }^{24}$ Incluso los más críticos de la expresión aceptan su autenticidad. Así: MEYLAN, Ph., Origine, cit. (n. 19), p. 507; Capogrossi Colognesi, L., Struttura, cit. (n. 18), I, p. 247; Bretone, M., Nozione, cit. (n. 19) p. 22 n. 4.

${ }^{25}$ Gaudemet, Jean, Observations sur la “manus”, en RIDA. 2 (1953), p. 326. 
de algunos miembros de la familia respecto al pater. Sería a lo menos extraño que, atendido el lenguaje tradicionalista de las leyes en Roma, se quisiese innovar referirse a la posición subordinada de los miembros de la familia utilizando una expresión como ésta, y más aún en una ley dirigida a otorgar la ciudadanía a una ciudad en Hispania. Lo propio habría sido que la innovación hubiese comenzado en el ámbito de la Jurisprudencia para sólo más tarde filtrarse a la legislación. Si se debe asumir que la expresión "potestas manus mancipio" no proviene al menos de época Republicana, sino que es una creación de tiempos imperiales, debe explicarse qué función cumple tal sintagma en una ley del siglo I como si fuese ya una expresión estereotipada ${ }^{26}$. Esta dificultad fue asumida por Meylan ${ }^{27}$ quien se pregunta, si la patria potestas y el estatuto subordinado de los miembros de la familia agnaticia eran propios del ius civile, y por tanto instituciones particulares del pueblo romano, como dice Gayo ${ }^{28}$, ¿qué función cumpliría tal fórmula en una ley de concesión de ciudadanía? Al respecto, el autor intenta una arriesgada teoría en que postula que el singtagma apuntaría a "potestate matrimoniove" refeririéndose la expresión "manu mancipio" a la mujer casada que ha celebrado una coemptio con su marido, lo que le otorga la calidad de matrona. Así el texto mantendría el estatuto de matrona de aquellas mujeres que lo eran (asumiendo que matrona significa mujer casada con un sui iuris que ha celebrado coemptio) antes del otorgamiento de la ciudadanía. La verdad es que la teoría de Meylan parece insatisfactoria. No sólo es bastante arriesgada, pues asume un significado concreto para matrona que está bajo debate ${ }^{29}$, sino, sobre todo, porque si el estatuto de alieni iuris es una particularidad del derecho romano, la manus y las formas de entrar en ella son aún más particulares ${ }^{30}$. La verdad es que no sabemos nada del Derecho salpensano, por lo que nos resulta muy difícil imaginar si es que tal ciudad tendría algo similar a la manus entre sus instituciones de familia y, mucho más difícil, si es que ese instituto admitiese una forma similar a la coemptio y que esa forma otorgase el estatuto de matrona. En pocas palabras, la teoría de Meylan crea más incertidumbres que aquéllas que intenta resolver.

En verdad, el punto es que la norma intenta mantener el estado de familia que tenían los nuevos ciudadanos en su propio derecho tradicional, dentro del nuevo

${ }^{26}$ En efecto, VOLTERra, Edoardo, Nuove ricerche sulla conventio in manum (1966), en Scritti giuridici (Napoli, Jovene, 1991), III, pp. 28-29, contra la opinión que refuta la validez de la expresión, alega que sería muy difícil encontrar un significado jurídico a alguna formulación distinta que potestas manus mancipioque

${ }^{27}$ Meylan, Ph., Origine, cit. (n. 19), p. 509.

${ }^{28}$ En efecto, señala al referirse a la potestas que ésta es propia de los ciudadanos romanos en Gai. 1,55 .

${ }^{29} \mathrm{Al}$ respecto véanse los dos más importantes trabajos en la materia, el primero y hasta hoy insuperado de KunKel, Wolfgang, "Mater familias”, en RE. (Stuttgart, 1930), XIV,2, pp. 2.183 ss., como también el interesante y minucioso trabajo de FIORI, Roberto, "Materfamilias", en BIDR., 25-26 (1993-1994).

${ }^{30}$ Podríamos también usar el testimonio de Gayo $(1,108)$ para afirmarlo, pues define la manus en este sentido, aunque tampoco vale la pena insistir sobre el punto, puesto que Gayo no intenta hacer Derecho comparado cuando realiza estas puntualizaciones, sino más bien hacer entrar las instituciones del ius civile o gentium. 
marco jurídico que les otorga la ciudadanía. Si bien es cierto que, al conceder la ciudadanía a pueblos distantes cuyas costumbres varían mucho de las de Roma, difícilmente se encontrarán equivalencias para la mayor parte de las instituciones de Derecho de familia, si la ley hubiese sido otorgada a favor de un pueblo más cercano culturalmente de Roma, tal vez la norma habría tenido más utilidad.

En este contexto, dicha norma parece diseñada para resolver un problema concreto, que se ha generado más de una vez cuando pueblos, cuyas instituciones jurídicas son culturalmente cercanas a las de Roma, cambiaban su estatuto de ciudadanía y, por tanto, enfrentaban seriamente el riesgo de conflictos entre el nuevo estatuto de ciudadano y el estado de familia que tenían sus miembros antes de tal adquisición. De ahí se explicaría el estilo analítico del tratamiento de los casos que puedan darse, intentando cubrir el máximo de situaciones posibles y evitando que queden puntos sin tratar, como, por ejemplo, cuando dice "consecutus consecuta erit", efectuando una partitio para incluir expresamente a hombres y mujeres.

Por otro lado, atendido el uso de formularios en la práctica jurídica romana, la lex Salpensana no parece ser un instrumento único diseñado exclusivamente para la ciudad de Salpensa, sino que se basa en un formulario general que se utiliza para la mayoría de los municipios ${ }^{31}$ y es posible encontrar equivalencias entre todos ellos, incluso varios de mayor antigüedad que nos llevan directamente al período de las guerras sociales, como es el caso de la ley municipal de Tarento ${ }^{32}$. Así, por ejemplo, las leyes de Malaga y Salpensa son muy cercanas temporalmente, tanto como para completar las disposiciones de una en base a la otra, mientras que por otro lado, existen entre los estatutos de Malaga y Tarento disposiciones gemelas ${ }^{33}$, lo que indica que la formula general para las leyes municipales no es de época imperial, sino del período republicano.

En el contexto del otorgamiento de la ciudadanía a pueblos cercanos cultu-

${ }^{31}$ En efecto, D’Ors, Álvaro, Un aviso sobre la “ley municipal”, lex rescripta, en Mainake, 23 (2001), pp. 97-100, postula que se fundaba en un formulario general utilizado por Augusto para todos los municipios italianos.

${ }^{32}$ Aunque la información con que contamos para los diversos municipios es muy fragmentaria, podemos, eso sí, encontrar suficientes equivalencias entre los distintos textos como para remontar el camino hacia un modelo base común a todas las leyes municipales. Véase: GIRARD, P. F. - SenN, F., Les lois des Romains, cit. (n. 22). p. 188.

${ }^{33}$ La disposición 4 de la Ley de Tarento señala: "Nei quis in oppido quod eius municipi e $[\mathrm{r}]$ it aedificium detegito neive dem [olito] | neive disturbato, nisei quod non deterius restituturus erit, nisei $d[\mathrm{e}]$ s(enatus) $s$ (ententia). | sei quis adversus ea faxit, quant $[\mathrm{i}]$ id aedificium $f[\mathrm{u}]$ erit, tantam pequni [a] $m \mid$ municipio dare damnas esto, eiusque pequniae [que] i volet petiti[o] esto. | magi(stratus) quei exegerit dimidium in $[\mathrm{p}]$ ublicum referto, dimidium in $l[\mathrm{u}]$ deis, quos $\mid$ publice in eo magistratu facie $[\mathrm{t}$ ] consumito, seive ad monumentum suom | in publico consumere volet, $l$ [icet] idque ei s(ine) $f$ (raude) s(ua) facere liceto"; mientras que la disposición 62 de la Ley de Malaga dispone: "Ne quis in oppido municipii Flavii Malacita|ni quaeque ei oppido continentia aedificia | erunt, aedificium detegito destruito demo|liundumve curato, nisi [de] decurionum con|scriptorumve sententia, cum maior pars $\mid$ eorum adfuerit, quod restitu[tu] rus intra proxi|mum annum non erit. Qui adversus ea fece|rit, is quanti e(a) r(es) e(rit), t(antam) p(ecuniam) municipibus municipi | Flavi Malacitani $d$ (are) d(amnas) e(sto), eiusque pecuniae | deque ea pecunia municipi eius municipii, |qui volet cuique per $h(\mathrm{anc}) l(\mathrm{egem})$ licebit, actio petitio \| persecutio esto". 
ralmente a Roma, como son aquellos itálicos que obtuvieron su ciudadanía en el período de las guerras sociales, parece haber adquirido su forma final el formulario general para la leges municipales como forma legal preredactada para otorgar el estatuto de romanidad a una ciudad aliada. Por lo demás, fue en esa época en que Roma se vio forzada a redactar leges municipales en masa a fin de atender a los nuevos estatutos de ciudadanía que sus antiguos aliados habían conseguido, por lo que el diseño de un instrumento único que sirviese de base para todos los demás se volvió una necesidad. Esta tesis, defendida recientemente con acierto por Lamberti ${ }^{34}$, nos lleva un espacio cultural y jurídico en que tendría sentido la inclusión de una cláusula que conserve el status familiae de los beneficiarios, puesto que, aunque la manus o la patria potestas son propios del Derecho romano, es probable que existiesen instituciones equivalentes entre los pueblos latinos beneficiados por tal conseción, o incluso entre otros pueblos de raíz étnica no latina que hubiesen adoptado institutos similares por asimilación cultural luego de haber recibido el estatuto de latinidad o de haber permanecido bajo la influencia cultural romana por largo tiempo.

En pocas palabras, la inclusión en la lex Salpensana de la fórmula potestas manus manicipioque no es prueba de que el sintagma, y por tanto la tripartición de los poderes del paterfamilias, se hubiese acuñado en época imperial, sino muy por el contrario, nos lleva, al menos, a la época de las guerras sociales. Sin embargo, la tripartición podría ser más antigua, pues si consta legislativamente en tal período, debió haber sido elaborada conceptualmente antes del mismo para permear en la técnica legislativa romana.

El siguiente documento a estudiar al respecto es la misma lex Cincia (204 a. C.), cuyo texto conservamos a través de una cita de Paulo incluída en los Fragmenta Vaticana. El primero es FV. 298: "Paulus libro LXXI ad edictum, ad Cinciam. Personae igitur cognatorum excipiuntur his uerbis : 'siue quis cognatus cognata inter se, dum sobrinus sobrinaue propiusue eo sit, siue quis in alterius potestate manu $m$ [ancipioue] erit, qui eos hac cognatione attinget quorumue is in potestate $m$ [anu mancipio] ue erit, eis omnibus inter se donare capere liceto'”. El segundo es FV. 300: "Item. Excipiuntur et ii, qui in potestate eorum uel manu mancipioue, item quorum in potestate manu mancipioue erunt".

Aquí hemos transcrito la versión tradicional de Mommsen ${ }^{35}$, pero en lo relativo a la inclusión del sintagma, las principales versiones alternativas mantienen la corrección mommseniana ${ }^{36}$. Al respecto, el fragmento presenta un problema

\footnotetext{
${ }^{34}$ Lamberti, Francesca, “Civitas Romana” e diritto latino fra tarda repubblica e primo principato, en Index, 39 (2010), pp. 227-235.

${ }^{35}$ Incluida en Mommsen, Theodor, Collectio librorum iuris anteiustiniani (Weidmannos, 1890, Berlín), III.

${ }^{36}$ Así, Bruns, Carl Georg, Fontes iuris romani antiqui (Tübingen, Karl Georg, 1909): "sive quis cognatus cognata inter se, dum sobrinus sobrinave propiusve eos, et sive quis in alterius potestate manu mancipiove erit, qui eos hac cognatione attinget, quorumve <is $>$ in potestate manu mancipiove erit, eis omnibus inter se donare capere liceto". Y CRAWFORD, Michael, Ancient Roman Statutes (London, Institute of Classical Studies, 1996), II: "siue quis cognatus cognata inter se, dum sobrinus sobrinaue propiusue eo $s<\mathrm{i}>t$, siue quis in alterius potestate $<\mathrm{manu}$ mancipioue $>$
} 
de lectura puesto de relieve por Casavola ${ }^{37}$. En FV. 298, cuando se cita el texto de la lex Cincia, se utiliza una notación resumida que reza "mmniove" y no " $m a$ nus mancipiove”. Mommsen estimó que la lex Cincia debía definir las personas bajo dependencia en los mismos términos que ocupa Paulo en FV. 300, esto es utilizando la expresión "in potestate manu mancipiove”, aunque el manuscrito Vaticanus 5766 no señala esto ${ }^{38}$. En efecto, la lectura más simple de "mmniove" es, naturalmente, "matrimoniove", cuestión que puntualizó Casavola y en lo cual ha sido generalmente seguido por los autores que han vuelto sobre el tema ${ }^{39}$. La gran excepción al respecto la constituye Volterra ${ }^{40}$, quien ha desechado directamente posibilidad de reemplazar la lectura tradicional de "in potestate manu mancipiove" por "in potestate matrimoniove" haciendo notar que parece carecer de sentido jurídico la nueva lectura propuesta. En efecto, afirma que esta locución ("in potestate matrimoniove"), no se encuentra en ninguna otra fuente, mientras que el trinomio tradicional constituye un sintagma muy usado y pleno de sentido en la ciencia jurídica romana. Por lo demás, el mismo cardenal Angelo Mai, y no Mommsen, habría sido el primero en realizar la corrección de "mmniove" a "manu mancipiove" 41 .

La verdad es que resulta difícil tomar partido en la compleja discusión filológica relativa al fragmento. Hay, sin embargo, tres problemas que deben ser abordados antes de decirdirse por alguna de las dos posibilidades. En primer término está el problema del método empleado por Mommsen para interpretar el vacío; en segundo, el lenguaje jurídico romano y la mayor o menor concordanca de las distintas lecturas del texto con éste y en tercer término, el significado dogmático que podría tener variar la interpretación tradicional.

Respecto a la técnica de Mommsen, la verdad es que de la abreviatura se lee más naturalmente "matrimoniove" que "manu mancipiove", aunque esto no debe ser exagerado. Si en parágrafo 300, cuya lectura no se discute, que proviene del mismo libro y donde Paulo se refiere a la misma materia ampliando su interpretación sobre el problema, el jurista señala que también están exceptuados de la prohibición aquéllos que está en potestas, manus o mancipium de aquellas personas que están exceptuadas por ser alieni iuris y estar in potestate manu mancipioue, resulta difícil leer otra cosa en el fragmento 298 donde se cita la lex Cincia que el viejo trinomio mommseniano. En efecto, FV. 300 es una ampliación de la norma citada en FV. 298 y no se entiende por qué el jurista habría variado el lenguaje de la ley. Si FV. 298 hubiese dicho, efectivamente, "potestas matrimoniove", ¿qué tiene que ver el mancipio en todo esto? ¿Por qué Paulo habría dicho que las personas que están

erit qui eos hac cognatione attinget, quorumue in potestate <manu mancipioue > erit, eis omnibus inter se donare capere liceto".

${ }^{37}$ Casavola, M., Lex Cincia, cit. (n. 19), pp. 58-60

${ }^{38}$ Para una historia del manuscrito, véase: Betancourt, Fernando, El libro anónimo "de interdictis”. Codex Vaticanus Latinus 5766 (Sevilla, Universidad de Sevilla, 1997), pp. 51-521

${ }^{39}$ Meylan, Ph., Origine, cit. (n. 19), pp. 503-513; Capogrossi Colognesi, L., Struttura, cit. (n. 18), I, p. 151; Bretone, M., Nozione, cit. (n. 19), p. 22 n.4.

${ }^{40}$ Volterra, E., Nuove ricerche, cit. (n. 26).

${ }^{41}$ Ibíd., pp. 28-29. 
en potestas manu mancipiove de aquéllas que están en potestas manu mancipiove también están exceptuadas? La interpretación de Paulo intenta exceptuar de la prohibición a personas como el nieto o la nuera casada que ha celebrado conventio in manu, y de ahí que señale que no sólo están exceptuados de la prohibición de donaciones de la lex Cincia el hijo de familia o la mujer casada cum manu, sino también quienes están bajo la dependencia de estas personas y, para definirlas, utiliza el trinomio. Si tal trinomio no estuviese en la norma original, no tendría sentido ampliar el ámbito de las personas bajo dependencia utilizándolo. El fragmento tiene toda la apariencia de una interpretación del sentido original de una disposición, por lo que sería difícil que el jurista intentase interpretarla variando las palabras de la ley. Por lo demás, el sentido dogmático de la interpretación de Paulo salta a la vista si asumimos que utiliza el trinomio, mientras que si suponemos que la norma decía sólo “in potestate matrimoniove” no se entiende. Las personas que están bajo potestas, manus o mancipium no tienen un patrimonio, sino que todo lo que adquieren se imputa al patrimonio del paterfamilias ${ }^{42}$. Es por ello que parece natural que la lex Cincia los exceptúe de la prohibición de donaciones, toda vez que el pater, cuando les dona algo, no realiza, en la práctica, ningún acto de consecuencias patrimoniales. Es, de alguna manera, como sacarse algo de un bolsillo para ponerlo en el otro. En este mismo sentido, las personas que están bajo potestad, manus o mancipio de éstos, tampoco tienen autonomía patrimonial, por lo que una donación realizada por el pater (en este caso el abuelo o el suegro) tendría los mismos efectos que en el caso anterior, puesto que todos los actos de adquisición revierten en el patrimonio del mismo pater.

Si el texto de la lex Cincia dijese, en cambio, "potestas matrimoniove", entonces sí que se crearía una situación anómala, puesto que el matrimonio sine manu parece haber sido algo común en la época de la lex $\mathrm{Cincia}^{43}$, por lo que, en caso que la mujer se hubiese casado sine manu, quedarían exceptuadas donaciones que efectivamente salen del patrimonio del pater para radicarse en otro distinto al suyo $y$, por tanto, que quedarían fuera de su capacidad patrimonial. Aunque es posible que la lex Cincia autorizara esto, sería extraño que lo hiciese junto con el caso de las personas sometidas a potestas, donde el acto de disposición del pater no hace otra cosa sino engrosar el peculio del beneficiado, más no escapar de su ámbito patrimonial. En pocas palabras, la manus y la potestas tienen efectos patrimoniales simétricos, por lo que autorizar las donaciones a favor de los sometidos a potestas es análogo a validarla para quienes están bajo manus, mientras que el matrimonio, por sí mismo, y más aun en la época de la lex Cincia, no coloca a la mujer en

\footnotetext{
${ }^{42}$ Gai 2,86: "Adquiritur autem nobis non solum per nosmet ipsos, sed etiam per eos, quos in potestate manu mancipioue habemus [...]".

${ }^{43}$ Cómo ejemplos de mujeres casadas que actúan con patrimonio propio, y que por tanto no se han sometido a la manus de sus maridos antes de la lex Cincia, podemos citar: el caso de aquéllas mujeres que realizaron una contribución al templo de Apolo después de la toma de Veyes (395 a.C., LIV. V,25,8); la aportación de las mujeres al rescate de la ciudad durante el sitio de los galos (390 a. C., Liv. V,50,7) y las multas a las matronas que comietieron adulterio en 290 a.C. (Liv. $\mathrm{X}, 31,9)$. Para todos estos casos, véase: HANARD, Gilbert, "Manus" et mariage a lépoque archaïque, en RIDA., 26 (1989), pp. 197-198; y también AmunÁTEGuI, Carlos, Casos de matrimonios "sine manu" en tiempos arcaicos, en Revista General de Derecho Romano, 10 (2008).
} 
una situación similar a la de los hijos de familia, por lo que se contemplarían en la ley dos supuestos heterogéneos y difícilmente analogables. La corrección, en este aspecto, parece resultado de la madura reflexión, no sólo de Mommsen, sino también de Angelo Mai.

Por último, hay un aspecto más que no ha sido tomado en consideración al respecto. La locución "in alterius potestate $m$ [atrimonio]ve erit" supone un giro lingüístico poco común en el latín clásico. En efecto, la expresión “in matrimonio esse" que subyace al texto es extremadamente inusual en el período. Lo común es combinar la expresión "in matrimonio" con el verbo "habere" ${ }^{44}$ para denotar que el estado de casado, mas la combinación con el verbo ser es bastante rara y propia del período final del Principado ${ }^{45}$. Si la lex Cincia hubiese empleado tal combinación, habría sido la primera en la historia del latín en hacerlo, lo que parece improbable. Si sumamos a esto el hecho que la expresión "potestas manus mancipiove" parece encontrarse en lenguaje legislativo republicano para la época de las Guerras Sociales, según concluímos más arriba, la tesis de Casavola parece bastante improbable y nos vemos forzados a inclinarnos en favor de la lectura mommseniana que contemplaría la locución "potestas manus mancipiove" en la lex Cincia.

La consecuencia inmediata de tal aceptación es considerar que los poderes del paterfamilias se encuentran diferenciados según el objeto sobre el cual se ejercen ya en el 204 a.C. y seguramente antes. Las implicancias de esta afirmación serán objeto del siguiente acápite.

\section{Poderes PATERNOS Diferenciados}

Si la lectura tradicional de la lex Cincia se corresonde con la tesis de Mommsen, entonces debe aceptarse que ya a fines del siglo III a. C. el conjunto de poderes del paterfamilias se encontraba diferenciado y que eran usualmente expresados con el trinomio potestas manus mancipioque. El lenguaje legal romano era, si cabe, más conservador que aquél perteneciente a las ciencias jurídicas en general y una innovación en éste dice relación con una larga historia evolutiva dentro del vocabulario del Derecho, iniciada, generalmente, por el estamento de juristas. El principal problema al respecto es que, encontrándonos en un período tal como el s. III a. C, lo que un día será la gran Ciencia jurídica romana se encuentra en plena formación, mientras que el lenguaje jurídico y su control se encuentran aún en manos del colegio de los pontífices. Podríamos intentar explorar el mundo de los cambios en los usos sociales del lenguaje para detectar la aparición del trinomio, pero, lamentablemente, para el período en cuyo estudio nos encontramos inmersos,

${ }^{44}$ Así, Cic., p. Quinct. 16,7; In Verr. 2,2,89,7; In Verr. 2,3,168.6; BRUT. 14,2,2; Liv. XXXIV,5,3; Cornelius Nepos Vit. pr. 1,4,2 y Vit. Di. 1,1,3; Suet., v. Cal. 7,1,1.; Tacitus, Ann. 12,46,4; Valerius Maximus, Mem. 6,2,3,9 y 7,7,3,2; D. 24,2,10 pr.- 1.

${ }^{45}$ Así, sólo aparece como "in matrimonio fuit" en dos fragmentos: D. 24,3,7 pr. y 24,3,7,13, ambos de Papiniano (11, quaest. div.), que, por cierto, no es un autor que se caracterice por su buen latín. También la encontramos como "in matrimonio est" en Dig. 49,15,12,4, que corresponde al libro $4^{\circ}$ disputationum de Tryphoninus, un autor bastante tardío. 
la literatura latina no ha nacido y, por consecuencia, no tenemos textos en los cuales basar nuestras hipótesis, con la salvedad de unos pocos fragmentos de la ley de las XII Tablas y casuales apariciones en la literatura posterior de alguno de estos términos. En pocas palabras, buena parte de lo que expongamos a continuación no tiene una base textual para apoyarse y deberá, necesariamente, constituir una suerte de adivinanza acerca del origen y función del trinomio.

Si queremos encontrar un significado al trinomio, lo primero es analizar si estos tres términos apuntan a poderes análogos en época arcaica y, específicamente, el alcance de estos poderes. Respecto a "manus" y "potestas", no parecen existir mayores dudas. Ambos parecen referirse a poderes de carácter personal, la manus a aquél que ejerce el marido sobre la mujer que se ha sometido a conventio in manum y la potestas a aquel que detenta el pater sobre los hijos de familia ${ }^{46}$. Aunque desde el siglo XIX se ha intentado establecer que el término “manus" tenía también un uso más amplio ${ }^{47}$, de momento no queremos entrar en este debate. Lo mismo debemos señalar respecto a la identidad nominal - potestas- entre el poder que se ejerce sobre los hijos y los esclavos. Lo importante para nosotros, en esta etapa, es que ambos términos tenían un carácter potestativo. El debate se ha centrado en torno al tercero de estos términos, "mancipium", y la posibilidad que tal expresión tuviese, en etapa arcaica, un sentido en que se refieriese a un poder. El debate se encendió cuando De Visscher ${ }^{48}$ identificó “mancipium” con un poder similar a la soberanía, una suerte de poder de comando sobre cosas y personas. Su interpretación de la voz excluía que la palabra apuntase a un acto, sino que siempre tendía a identificarse con un poder. Tal teoría fue generalmente rechazada ${ }^{49}$, al punto que hoy por hoy parte de la crítica niega rotundamente la posibilidad de que elm término "mancipium" apunte en ningún caso a un poder dentro del vocabulario $\operatorname{arcaico}^{50}$, mientras que otro grupo limita su valor potestativo sólo al ámbito de las personas adquiridas a través de la mancipatio ${ }^{51}$

$\mathrm{Al}$ respecto, se encuentran documentados varios casos en que la voz " mancipium" parece referirse a la mancipatio como acto. En efecto, el nombre más antiguo de la mancipatio parece haber sido "mancipium" 52 . El estudio más sugerente

\footnotetext{
${ }^{46}$ Franciosi, G., Famiglia, cit. (n. 17), p. 44; Serrao, F., Diritto privato, cit. (n. 13), I, p. 196

${ }^{47}$ Voigt, M., Röm. Rechtgesch., cit. (n. 12), I, p. 348; Bonfante, P., Corso. La proprietà, cit. (n. 12), II,1, p. 230; LeIFER, F., "Mancipium", cit. (n. 12), p. 154; KASER, M., Eigentumsbegriff, cit. (n. 12), II, p. 52; CASINOS Mora, F. J., “Auctoritas", cit. (n. 12), p. 77; FuENTESECA Degeneffe, M., Formación, cit. (n. 12), pp. 26-135.

${ }^{48}$ De Visscher, F., "Mancipium", cit. (n. 11), p. 286. En el mismo sentido: Leifer, F., "Mancipium", cit. (n. 12), p. 154

${ }^{49}$ Diósdi, G., Ownership, cit. (n. 13), p. 52; Bonfante, P., Corso. La proprietà (n. 12), II,1, p. 253; Bretone, M., Nozione, cit. (n. 19), p. 23; Levy-Bruhl, Henri, Autour de la "mancipatio familiae", en Atti del congreso internazionale di Diritto romano e di Storia del Diritto (Verona) (Milano, Giuffrè, 1948), p. 71; SerRaO, F., Diritto privato, cit. (n. 13), I, p. 196.

${ }^{50}$ Capogrossi Colognesi, L., Struttura., cit. (n. 18), I, p. 254.

${ }^{51}$ Gallo, Filippo, Studi sulla distinzione fra "res mancipi" e "res nec mancipi", en Rivista di Diritto Romano, 4 (2004),. pp. 1-121, que es una reedición de sus Studi sul trasferimento della proprietà in diritto romano (Torino, Giappiuchelli, 1958), p. 79.

${ }^{52}$ Gallo, F., Studi sulla distinzione, cit. (n. 51), p. 47; Serrao, F., Diritto privato, cit. (n. 13), I, p. 194.
} 
al respecto pertenece a Gallo ${ }^{53}$, quien realiza un exhaustivo análisis de las voces "mancipium" y "mancipatio" en la obra de Gayo. Al respecto, da una solución a algunos de los aparentes glosemas que creía haber detectado Solazzi ${ }^{54}$ señalando que algunas incoherencias lingüísticas contenidas en las Institutas se deberían a que Gayo reemplazó la voz "mancipium” por "mancipatio" en varios puntos centrales de su descripción. La verdad es que la tesis es muy convincente y nosotros nos limitamos a adherir a ella en este aspecto.

El más famoso y discutido es, evidentemente, la disposición de las XII Tab. 6,1: "cum nexum faciet mancipiumque, uti lingua nuncupassit, ita ius esto" 55 . Es muy difícil sostener que mancipium signifique cualquier otra cosa que no sea un acto en este caso, sobretodo por su posisión análoga al nexum, que sabemos bien que constituye una operación jurídica, y por el verbo faciet que rige el caso ${ }^{56}$. El sintagma "nexum mancipiumque" ha dado mucho que pensar a la crítica y las teorías al respecto son abundantes. Así, un grupo de autores estima que ambas operaciones serían sinónimas o, a lo menos, que generarían una misma situación de dependencia, lo que justificaría su tratamiento conjunto en las XII Tablas ${ }^{57}$.

Otros creen que serían dos negocios distintos ${ }^{58}$, especialmente porque los nexi permanecen libres mientras que los mancipii no, sino que están sometidos a un poder, el mancipium, de sus adquirentes. Por lo demás, se argumenta que los ciudadanos romanos no son res mancipi, sino hombres libres, por lo que necesariamente la disposición debiese apuntar a dos tipos diferentes de actos, uno sobre cosas, mancipium, y otro sobre personas sui iuris, nexum. Por último, se señala que los hijos de quienes están in mancipio no están bajo mancipium, aunque los hijos de los nexi si $^{59}$.El problema, naturalmente, nos remite a la relación entre el nexum y el mancipium en general, materia en que la doctrina ha sido particularmente abundante aunque poco concluyente. Podemos decir que la crítica, en general, ha centrado la discusión en torno a la posibilidad de identificar el nexum con la mancipatio o pensar que el nexum es alguna clase de préstamo libral de naturaleza diferente. Básicamente podemos distinguir las teorías según la naturaleza que

${ }^{53}$ Ibíd., pp. $45-70$

${ }^{54}$ Solazzi, Siro, Glosse a Gaio, en Studi in onore a Salvatore Riccobono (Palermo, 1936), I, p. 154

${ }^{55}$ El texto está tomado de FEsTO, De verb. 173,11: "Nuncupata pecunia est, ut ait Cincius in lib. II de officio iurisconsulti, nominata, certa, nominibus propriis pronuntiata: 'cum nexum faciet manci-piumque, uti lingua nuncupassit, ita ius esto': id est uti nominarit, locutusve erit, ita ius esto". Parece ser una cita textual del jurista Cincio, del siglo I a. C.;k véase: Albanese, B., "Cum nexum faciet mancipiumque", cit. (n. 13), p. 50.

56 Capogrossi Colognesi, L., Struttura (n. 18), I pp. 305-308. Sin embargo, la idea que mancipium en este caso signifique un poder ha sido defendida en más de una oportunidad: SARgEnTI, Manlio, Per una revisione della nozione dell" auctoritas" come effetto della "mancipatio", en Studi in onore di Emilio Betti (Milano, Giuffrè, 1962), IV, p. 46.

${ }^{57}$ Serrao, F., Diritto privato, cit. (n. 13), I, pp. 176-184; Albanese, B., “Cum nexum faciet mancipiumque", cit. (n. 13), p. 94.

${ }^{58}$ Kretschmar, P., Das “nexum”, cit. (n. 17); Kaser, M., Röm. Privatrecht (München, Beck, 1971), I, p. 166 n. 5; Tomulescu, Constantin, “nexum” bei Cicero, en Ivra, 17 (1966), p. 94.

${ }^{59}$ Se citan como apoyo: Val. Max 6,1; Liv. 8,28; y Dion. Hal. 6,26. Véase: Tomulescu, C., "Nexum" bei Cicero, cit. (n. 58), p. 94. 
otorgan a la institución; las dos más importantes son la tradicional de Huschke, según la cual el nexum es un contrato de préstamo libral, y la de Mitteis que lo entiende como un negocio automancipatorio.

Para la primera, el nexum es un contrato de préstamo por aes et libram. Esta es la teoría que podríamos llamar tradicional en virtud de la cual el nexum sería una suerte de contrato de carácter público que se realiza por la solemnidad de la balanza, en virtud del cual el acreedor tiene una manus iniectio extrajudicial sobre el deudor. El creador de la misma es Huschke $e^{60}$ y ha sido objeto de agria polémica. Hoy se encuentra prácticamente abandonada, toda vez que la stipulatio se demostró más antigua de lo pensado y la manus iniectio extrajudicial ha sido descartada por innecesaria ${ }^{61}$.

Según la segunda teoría, el nexum es un negocio automancipatorio en que el deudor, a través de un préstamo realizado en virtud de una mancipatio, entra bajo la dependencia del acreedor. La teoría pertenece a Mitteis ${ }^{62}$ y causó un verdadero terremoto jurídico en su época. Sobre todo se atacó la posibilidad que el mismo deudor fuese a la vez actor y objeto de la mancipación, como también la equiparación entre nexum y mancipatio ${ }^{63}$. El debate fue fuerte y se postularon diferentes posibilidades para solucionar la controversia ${ }^{64}$. Así, la variedad doctrinaria parece

${ }^{60}$ HuschKe, Philipp Eduard, Ueber das Recht des "nexum" und das alte römische Schuldrecht (Leipzig, Gebauer, 1846), seguido por BEKKER, Ernst Immanuel, Die Aktionen des römisches Privatrechts (Berlin, F. Vahlen, 1871).

${ }^{61}$ KaSER, Max, "Mores maiorum" und Gewohnheitsrecht, en ZSS., rom. Abt., 59 (1939), pp. 39 ss.

${ }^{62}$ MitTeis, Ludwig Ueber das “nexum”, en ZSS., rom. Abt., 22 (1901), pp. 96 ss.

${ }^{63}$ Lenel, Otto, Das "nexum”, en ZSS., rom. Abt., 23 (1902), pp 84 ss.; Kretschmar, P., Das “nexum”, cit. (n. 17), pp. 227 ss.

${ }^{64}$ Pflüger, Heinrich, "Nexum” und "mancipium” (Leipzig, Dunker \& Humblot), quie termina por confundir el nexum y la mancipatio (véase una crítica a esta teoría en MITTEIS, Ludwig, en ZSS., rom. Abt., 29, pp. 498 ss.); Mommsen, Theodor, “Nexum”, en ZSS., rom. Abt., 23 (1902), pp. 348 ss., que intenta una solución intermedia en que el nexum sería un contrato de préstamo cuya ejecución se realizaría mediante la mancipatio del deudor; PACCHIONI, Giovanni, "Nexum". Impressioni e reminiscenzi, en Melanges Paul Frédéric Girard (reimpresión Aalen, Scientia, 1979), II, pp. 319 ss. que lo pone en relación con el ius noxae dandi en una teoría que unifica la responsabilidad delictual y pecuniaria dentro de la óptica automancipatoria; LENEL, O., cit. (n. 63), que lo une al vadimonium; IMBERT, Jean, "Fides" et "nexum", en Studi in onore di Arangio-Ruiz (Napoli, Jovene, 1953), I, pp. 338, que ilumina la oscuridad del nexum con otro concepto más oscuro, diciendo que el nexum es un acto libral que deja al deudor bajo la fides del acreedor; BeHrends, Okko, La “mancipatio" nelle XII Tavole, en Ivra, 33 (1982), pp. 46 ss., que lo mira como una manera de transferir los inmuebles, que según el autor no serían objeto adecuado para la mancipatio. FuenTESECA, Pablo, "Mancipium-mancipatio-dominium", en Labeo, 4 (1958) 2, pp. 135-149, estima que nexum sería el acto de alienación y mancipium se referiría al esclavo en este caso, lo cual es algo extraño, puesto que pone un acto y un objecto en bajo el mismo verbo y en el mismo caso. ¿Debiese leerse "Cuando nexum y esclavo hiciese"? No parece una hipótesis bien construida desde el punto de vista lingüístico. Otro caso es el de Westbrook, Raymond, Restrictions on Alienation in Early Law, en BirKs, Peter (editor), New Perspectives in the Roman Law of Property. Essays for Barry Nicholas (Oxford, Clarendon, 1989), que estima que sería un caso análogo a otros del cercano oriente, donde se vende y prenda la cosa al mismo tiempo, donde mancipium apuntaría al acto de alienación y nexum al de venta. No 
amplia, aunque con la salvedad de ciertas opiniones heterodoxas, parece que la opinión de Mitteis es ya mayoritaria, aunque no dominante.

En primer término, y a pesar de las objeciones que se han opuesto, hoy por hoy puede considerarse como un hecho establecido que el nexum es un tipo de negocio libral ${ }^{65}$. Respecto a la clase exacta de negocio libral de que se trata, aparentemente existió disputa entre los mismos juristas republicanos, de la cual nos da noticia el célebre fragmento de Varrón, De ling. Lat. VII,105: "In Colace: 'nexum' Manilius scribit, omne quod per libram et aes geritur, in quo sint mancipia. Mucius, quae per aes et libram fiant ut oblige[ $n]$ tur, praeter quom mancipio de $<n>t u r$. hoc verius esse ipsum verbum ostendit, de quo qu<a>erit: nam id <a>es [t] quod obligatur per libram neque suum fit, inde nexum dictum".

En efecto, el fragmento nos da noticia de una diferencia de opiniones entre dos juristas republicanos, donde el más antiguo, Manilio, identifica el nexum con el género, siendo los demás actos librales especies, incluyendo la mancipatio. Mucio, a quien Varrón apoya, prefiere excluir la mancipatio del término "nexum”, puesto que este último sería un acto libral, pero de naturaleza obligatoria. En verdad, con sólo observar el fragmento se comprende que la disputa que existe hasta hoy en la doctrina echa raíces en las mismas fuentes. Así, quienes conceptualizan el nexum como un negocio mancipatorio suelen otorgar prioridad a la primera parte del fragmento ${ }^{66}$, alegando usualmente que esa sería la opinión más antigua en la materia. Al contrario, quienes enfocan el nexum como un negocio de carácter esencialmente obligacional suelen preferir la segunda sección del mismo ${ }^{67}$, arguyendo que sólo con posterioridad y mediante una evolución se habría llegado a la significación que identifica el nexum y la mancipatio ${ }^{68}$. Objetivamente, albergamos pocas esperanzas de determinar si originalmente el nexum era un negocio sólo obligatorio o también mancipatorio, pues ni los mismos romanos eran capaces de convenir en ello. En todo caso, la idea que identifica el nexum y la mancipatio consta también en la obra de Gayo ${ }^{69}$. Por el momento, nos basta con constatar que el nexum sería un negocio libral, muy similar a la mancipatio y probablemente con un grado de parentesco respecto a ella.

Otro aspecto importante es que, siguiendo a Westbrook, la expresión "nexum mancipiumque" es cumulativa ${ }^{70}$ y no alternativa, como suele leerla la crítica. Volveremos sobre esto un poco más adelante, aunque nos interesa hacer notar

obstante, tiene el enorme mérito de subrayar que la lectura "nexum mancipioque" es cumulativa y no alternativa como la doctrina suele considerarla.

${ }^{65}$ Las referencias al respect son bastante claras: FEST., Verb. 165,20: "Nexum est, ut ait Gallus Aelius, quodcumque per aes et libram geritur: id quod necti dicitur. Quo in genere sunt haec: testamenti factio, nexi datio, nexi liberatio"; CIC., De orat. 3,159: "Nam si res suum nomen et vocabulum proprium non habet... ut nexum, quod per libram agitur [...]".

${ }^{66}$ Véase: MitTeis, L., Ueber das "nexum", cit. (n. 62), pp. 100 ss., como también BeHrends, O., La "mancipatio" nelle XII Tavole, cit. (n. 64), pp. 80 ss.

${ }^{67}$ Véase: Mommsen, Th., "Nexum", cit. (n. 64) pp. 348 ss.

${ }^{68}$ Véase Tomelescu, C., "Nexum" bei Cicero, en Ivra, 17 (1966), pp. 103 ss.

${ }^{69}$ Gai 2,27 : "aliter enim ueteri lingua a $<$ ctus uocatur, et quod illis nexus, idem nobis est> mancipa<tio>”.

${ }^{70}$ WestBRook, R., Restrictions, cit. (n. 64), p. 209. 
que, de conformidad a esta lectura de nexum y mancipium como expresiones cumulativas, es menester que se hayan realizado ambas a fin que el consecuente de la disposición, uti lingua nuncupassit, ita ius esto, se produzca. Es decir, de la lectura superficial de la misma debiese derivarse que no basta con realizar un nexum o una mancipatio para que las nuncupationes tengan plena fuerza, sino ambas. Independientemente que la jurisprudencia pontifical y laica, siglos más tarde, hayan construido a partir de este fragmento una cierta libertad negocial que permitió transformar a la mancipatio en un acto flexible y adaptable a todo tipo de situaciones jurídicas que se pretendiese crear, en su origen, el antecedente de la disposición exige una concurrencia de dos actos, el nexum y el mancipium, para que el consecuente pueda operar. Esto nos aproxima a la idea que debiesen ser dos actos diferentes, aunque su naturaleza está por discutirse. En principio, el nexum es un negocio de carácter crediticio, de la misma manera que la primitiva mancipatio sería una compraventa real, sólo que por las consecuencias sociales que tal vínculo tenía para el deudor, fue prohibido por la lex Poetelia Papiria en el 326 a.C., sin que llegase a evolucionar por nuevos derroteros, a diferencia de lo que sí sucedió con la mancipatio.

Como hemos visto, se discute si se articulaba como un acto libral obligatorio al que luego, en caso de insolvencia, sucedía una verdadera mancipatio ${ }^{71}$, una in iure cessio ${ }^{72}$ u otra figura similar ${ }^{73}$, o más bien como una automancipación que dejaba al deudor ya en poder de su acreedor ${ }^{74}$. Antes de responder a esta interrogante, intentaremos describir la calidad que dicho deudor o nexus tomaba por este acto.

Uno de los aspectos más seguros del nexum es que en virtud de éste el deudor debía trabajar en condición servil para su acreedor, como lo dice Varro, De ling. Lat. VII,105: "liber qui suas operas in servitutem pro pecunia quam debebat, dum solveret, nexus vocatur, ut ab aere obaeratus. hoc C. Poetelio Libone Visolo dictatore sublatum ne fieret, et omnes qui bonam copiam iurarunt, ne essent nexi, dissoluti".

En otras palabras, ocupaba la condición de un esclavo trabajando para su acreedor hasta que su deuda quedara satisfecha. Sin embargo, y a pesar de esta condición servil en que se encuentra, no es propiamente un esclavo, sino que sólo ocupa el lugar de éstos, lo que se manifiesta no sólo en la voz "liber" que utiliza Varrón, sino además que en otro texto se afirme explícitamente que conserva su ingenuidad ${ }^{75}$. Hoy por hoy podemos dar por seguro que la persona que quedaba como nexus mantenía su condición de ciudadano y militaba en el ejército ${ }^{76}$, es

\footnotetext{
${ }^{71}$ Mommsen, Th., “Nexum”, cit. (n. 64), pp. 348 ss.

${ }^{72}$ Tomelescu, C., “Nexum” bei Cicero, cit. (n. 68), pp. 39 ss.

${ }^{73}$ La idea de una manus iniecto extrajudicial está completamente descartada, sobre todo después de las críticas de KaSER, M., cit. (n. 61), pp. 39 ss.. En todo caso, por el vocabulario de las fuentes parece existir una suerte de auto entrega voluntaria de parte del deudor al poder del acreedor; véase: Tomelescu, C., “Nexum” bei Cicero, cit. (n. 68), pp. 57 ss.; y Mommsen, Th., "Nexum", cit. (n. 64), pp. 348 ss., para evitar la manus iniecto propiamente tal, que bien podría materializarse de esta manera.

${ }^{74}$ Mitteis, L., Ueber das “nexum”, cit. (n. 62), pp. 100 ss.; Pacchioni, G., "Nexum”, cit. (n. 64), pp. 319 ss.

${ }^{75}$ LIV. VIII, 28.

${ }^{76}$ Véase: Liv. II.24 y II.27, en donde se trata el problema del reclutamiento de los nexi.
} 
decir, que en el plano público su ingenuidad no se veía afectada.

En segundo lugar, tampoco podía ser maltratado ni injuriado por el acreedor ${ }^{77}$. En cuanto a su liberación, posiblemente se trate de la nexi liberatio que menciona Festo $^{78}$ la que seguramente se establecía en las nuncupationes correspondientes al acto. En todo caso, de seguro era obligatoria para el acreedor.

Esta segunda característica parece coincidir bastante bien con lo poco que sabemos de los hijos in mancipio, puesto que las consecuencias más importantes para el estatuto personal de un hijo de familia reducido al estado de in mancipio y que lo distinguen de un simple esclavo son que sus derechos políticos y obligaciones militares quedan intactas ${ }^{79}$; a consecuencia de ello, en el plano privado, no puede ser maltratado por el adquirente ${ }^{80}$ (por lo que a fortiori el mancipio accipiens no tendría ius vitae necisque sobre él) y, a diferencia de los esclavos, puede obligar al adquirente a liberarlo mediante el censo ${ }^{81}$. Como vemos, todas estas características son comunes entre el nexus y el hijo in mancipio, salvo en la manera de forzar al acreedor a su liberación.

Lo anterior ha llevado a la doctrina a excluir que los nexi estén en condición de esclavitud o que su situación sea analogable en manera alguna a los que han sufrido la manus iniecto. Ante ello, la doctrina debate si es que el nexus tenía la misma condición que el hijo dado in mancipio. Aquí las corrientes se dividen entre quienes están a favor ${ }^{82}$ y los que son contrarios a la misma ${ }^{83}$.

${ }^{77}$ De hecho, el abuso cometido por los acreedores respecto a los sujetos al nexum es la queja constante de la plebe; véase: LIV. II,23 y la correspondiente interpretación de WATSON, A., Rome, cit. (n. 15), pp. 112 ss. A mayor abundamiento, está la escena reportada por Valerio Máximo $(6,1)$ donde intervienen los cónsules para reprimir los abusos de un acreedor que quiere maltratar a un nexus.

${ }^{78}$ Verb. 165,23, de Aelius Galus Iur. 9,4.

${ }^{79}$ Gai. 1,162: "Minima est capitis diminutio, cum et ciuitas et libertas retinetur, sed status hominis conmutatur; quod accidit in his, qui adoptantur, item in his, quae coemptionem faciunt, et in his, qui mancipio dantur quique ex mancipatione manumittuntur; adeo quidem, ut quotiens quisque mancipetur aut manumittatur, totiens capite diminuatur".

${ }^{80}$ Gai. 1,141: "In summa admonendi sumus aduersus eos, quos in mancipio habemus, nibil nobis contumeliose facere licere; alioquin iniuriarum tenebimur. ac ne diu quidem in eo iure detinentur homines, sed plerumque hoc fit dicis gratia uno momento; nisi scilicet ex noxali causa mancipantur".

${ }^{81}$ Gai. 1,140: Quin etiam inuito quoque eo, cuius in mancipio sunt, censu libertatem consequi possunt, excepto eo, quem pater ea lege mancipio dedit", ut sibi remancipetur; nam quodam modo tunc pater potestatem propriam reseruare sibi uidetur eo ipso, quod mancipio recipit. ac ne is quidem dicitur inuito eo, cuius in mancipio est, censu libertatem consequi, quem pater ex noxali causa mancipio dedit, ueluti quod furti eius nomine damnatus est et eum mancipio actori dedit: nam hunc actor pro pecunia habet".

${ }^{82}$ Dentro del primer grupo, la postura más extrema pertenece a Mommsen, Th., "Nexum", cit. (n. 64), pp. 348 ss., que los asimila en todos los casos, mientras que un segundo grupo, representado por MARCHI, Antonio, Storia e concetto dell obbligazione romana (Torino, 1912), pp. 60 ss.; Watson, A., Rome cit. (n. 15), pp. 117 ss., limita esta equiparación para el caso de los hijos y demás descendientes entregados en nexum. Existe también una tercera vertiente de esta idea postulada por SChlossmann, Siegmund, "Nexum". Nachträgliches zum Altrömisches Schuldrecht (Leipzig, Deichert, 1904), pp. 1 ss. que señala que los nexados estarían en una situación de mancipatio fiduciaria; sin embargo esta visión debe ser desechada, puesto que supone la creación demasiado antigua de los negocios fiduciarios.

${ }^{83}$ Véanse: Tomelescu, C., “Nexum” bei Cicero, cit. (n. 68) pp. 84 ss.; Kretschmar, P., Das 
La postura contraria, que rechaza la equiparación entre nexus e hijo in mancipio, tiene varios argumentos que esgrimir, aunque de distinto peso. Los más utilizados son: $i$ ) los problemas a nivel teórico que presenta la automancipación; ii) la cuestión de si es o no aplicable la capitis diminutio al nexus; y iii) la segunda parte del fragmento de Varrón donde distingue al nexus de "quom mancipio dentur" donde se referiría a los hijos dados in mancipio según esta corriente. Sin embargo, ninguno de estos argumentos parece insuperable. Respecto al primero, no estamos en condiciones de ni de refutar ni de afirmar con toda seguridad la existencia de automancipaciones en el derecho romano, baste con pensar en las dudas que la coemptio presenta al respecto ${ }^{84}$. En cuanto a la capitis diminutio, es necesario recordar que se trata de una institución de la última República, es decir 270 años posterior al último nexum propiamente dicho, por lo que no es útil a la hora de evaluar el contenido original de la institución. Finalmente, en lo relativo a la última parte del fragmento de Varrón, debe recordarse que la primera parte del mismo, donde se cita la opinión del jurista más antiguo, incluye expresamente la mancipatio (y por tanto a los hijos in mancipio) dentro del nexum.

Hasta aquí tenemos dos aspectos importantes de la norma que debemos considerar a fin de dar una respuesta satisfactoria al enigma del sintagma "nexum mancipiumque”. En primer término, parece trantarse de dos actos diferentes, toda vez que la expresión utilizada por la Ley de las XII Tablas es cumulativa y requiere de la perfección de cada uno de ellos para que el consecuente opere. En segundo lugar, los nexi parecen estar también servorum loco, como los hijos in mancipio, es decir, bajo dependencia de otro a quien deben opera, pero con su ciudadanía y obligaciones militares intactas. Para dar el último paso en nuestra compresión de la norma, nos apoyaremos en una segunda disposición de las XII Tablas que ha sido generalmente descuidada por la crítica y parece tratar exactamente el mismo aspecto que la anterior. Nos referimos a la Tabula I, apartado 5, que en la versión de Girard ${ }^{85}$ se lee: "NEX[I MANCIPIIQUE --] FOR<C>TI SANATI[SQUe -- IUS ESTO]".

En verdad la disposición es intrigante, no sólo por su incompletitud, sino por la expresa referencia no a los actos de nexum y mancipatio, sino a los nexi y los mancipii propiamente tales. Lamentablemente, los fragmentos de donde ha sido tomada, especialmente de Festo, están muy incompletos por lo que su re-

“nexum”, cit. (n. 17) pp. 245 ss.L; PACCHIONI, G., “Nexum”, cit. (n. 64), pp. 323 ss.

${ }^{84} \mathrm{Al}$ respecto, RossBach, August, Untersuchungen über die römische Ehe (Stuttgart, K. Wäden, 1853), pp. 77 ss, seguido por Lenel, O., Das “nexum”, cit. (n. 63) pp. 84 n. 1, como consecuencia de su teoría que ve la coemptio como reminiscencia de un primitivo matrimonio por venta, cree que serán el pater o los tutores quienes reciban el as y de esta manera operen como mancipio dans en la coemptio. Karlowa, Otto, Römische Rechtsgeschichte (Leipzig, Veit, 1885), II, pp. 159, a la inversa, cree que será la propia mujer quien lo reciba, limitándose sus tutores o su pater a aprobar presencialmente la ceremonia. La pregunta es básicamente quién oficia como mancipio dans en la coemptio. La cuestión es demasiado sutil y la crítica tiende, hoy por hoy, a dejarla de lado; véanse: Corbett, Percy Ellwood, Roman Marriage (Oxford, Clarendon Press, 1930), pp. 80 ss.; Watson, A., Rome, cit. (n. 15), pp. 15 ss.; Treggiari, Susan, Roman Marriage (New York, Oxford University Press, 1991), pp. 25 ss.; Bonfante, P., Corso. Diritto di famiglia, cit. (n. 11), p. 65.

${ }^{85}$ Girard, P. F. - SenN, F., Les Lois des Romains, cit. (n. 22), p. 22. 
construcción es discutida. Al respecto, otros editores de la Ley de las XII Tablas dan una versión distinta. Así, Bruns ${ }^{86}$ y Riccobono ${ }^{87}$ leen sólo: "NEX ... FORTI SANATI ...”. Mientras que Crawford ${ }^{88}$ da una versión algo más larga: "NEX[Us (?) ---] FOR<C>TI SANATIQ[UE ---]”. Una lectura más amplia es dada por Huschke ${ }^{89}$ : "NEX[I MANCIPIIQUE CUM P.R. IDEM] FORTI SANATI[QUE SUPRA INFRAQUE ROMAN IUS ESTO]”. Esta última, tal vez la más aventurada, tiene el mérito de llenar todas las lagunas, aunque no ha sido seguida, especialmente porque requiere, en algún grado, adherir a la visión del nexum del propio autor.

La disposición ha sido muy poco comentada ${ }^{90}$, seguramente por lo discutible de su contenido y lo mutilado de los pasajes que le sirven de referencia. Al respecto, la norma aparece mencionada fundamentalmente de los varios fragmentos. El primero es Fest. 321: " $<$ Sanates quasi sana $>$ ti appellat $<i>$... Sulpicius ... et Opillus $<$ Aurelius $>$... dici inferio ... ut Tiburtes ... populo Tibur $<\mathrm{ti}>$... Tiburti, idem ... <infe $>$ riorisque loci ... in XII: "Nex <i> ... forti sanatid ... id est bonor $<\mathrm{um}>\ldots$ qui et inf ... que sunt $;. . .<$ pris $>$ cos Latinos ... egerit secundum ... <in $>$ fra Romam in $e$ ... eosque sanati ... praeter opinion $<\mathrm{em}>$... set sanavisse $<\mathrm{t}>q<\mathrm{ue}>$... cisci potuisset no ... Cincius lib. II de <officio iuriscon-> sulti. Ne Valerius <quidem Messala $>$ in $X I I$ explanatio $<$ ne $>$... men in eo libro, que $m$... volute inscribi, forc ... duas gentis finitimas ......<1>e gem hanc scrip<tam $>\ldots n$ ut id ius man<cipii nexique quod populu $>$ s Romanus haberent... . <fo $>r$ ctos et sana $<$ tes $>$... $<$ sig $>$ nificare exis- ... a tu. Multi sunt, ... acuit displi $<\mathrm{c}>$... u t. sant forcti ... < $>$ s anati insani".

El siguiente es Fest. 348: "Sanates dicti sunt, qui supra infraque Romam habitaverunt. Quod nomen his fuit, quia cum defecisse $<\mathrm{n}>t$ a Romanis, brevi post redierunt in amicitiam, quasi sanata mente. Itaque in XII cautum est, ut idem iuris esset Sanatibus quod Forctibus, id est bonis, et qui numquam defecerant a populo Romano]".

Sigue Gellius,. Noct. att. 16,10,6-8: "Petimus igitur, ne annalem nunc Q. Ennii, sed duodecim tabulas legi arbitrere et, quid sit in ea lege 'proletarius ciuis', interpretere. 'Ego uero' inquit ille 'dicere atque interpretari hoc deberem, si ius Faunorum et Aboriginum didicissem. Sed enim cum 'proletarii' et 'adsidui' et 'sanates' et 'uades' et 'subuades' et 'uiginti quinque asses' et 'taliones' furtorumque quaestio 'cum lance et licio' euanuerint omnisque illa duodecim tabularum antiquitas nisi in legis actionibus centumuiralium causarum lege Aebutia lata consopita sit, studium scientiamque ego praestare debeo iuris et legum nocumque earum, quibus utimur".

Si bien es cierto que Girard menciona algunos textos más, en verdad estos otros fragmentos no hacen sino reforzar la suposición que la norma contiene las palabras

${ }^{86}$ Bruns, C. G., Fontes, cit. (n. 36), pp. 15-40.

${ }^{87}$ Riccobono, S., FIRA., I, pp. 21-75.

${ }^{88}$ Crawford, M., Ancient Roman Statutes, cit. (n. 36), n. 40.

${ }^{89}$ Huschke, Ph., Über das Recht des “nexum”, cit. (n. 60), p. 255.

${ }^{90}$ Nosotros sólo tenemos como referencias a RosEnberg, Arthur, Zur Geschichte des Latinenbundes, en Hermes, 54 (1919) 2, pp. 113-173, que en su página 127 menciona incidentalmente el caso y asocia a los forti y sanates los pagi y a ELMORE, Jefferson, Recovery of Legal competency in the XII Tables, en Classical Philology, 20 (1925) 1, pp. 62-64, que en un brevísimo artículo da cierta luz sobre el problema. Volveremos sobre este último más adelante. 
"nexi mancipiique", cuestión que justamente entraremos a debatir. En primer término, se encuentra el sintagma "forti sanatique". Su significado no era claro ni siquiera para los romanos. $\mathrm{Al}$ respecto, de Fest. 348 se desprende una extraña leyenda sobre algunas comunidades que habrían hecho defección a los romanos y que, luego, una vez reconciliados, habrían sido restituidos a su viejo estatuto, como si hubiesen perdido la razón y luego se hubiesen recobrado, llamándose entonces "sanati", quienes se encontrarían en la misma posición que quienes no hicieron defección, los "fortes". No sabemos cuanto pueda haber de cierto en la leyenda, pero, en principio, la norma parece igualar a los que han perdido el juicio, pero se han recuperado, con los que nunca lo han hecho. En efecto, en el muy mutilado Fest. 322 se lee "praeter opinion<em>", contraponiendo la idea primeramente expuesta y citando al jurista republicano Cincius que parece hablar de los sanati sólo como aquéllos que se han recuperado de una enfermedad mental. Aunque los detalles de la leyenda puedan ser confusos y, probablemente, descartables, parece que la norma se refiere a quienes han sufrido un problema de salud, puede que mental ${ }^{91}$. En efecto, dentro del lenguaje jurídico, el único caso que tenemos en que se use la palabra "sanatum" es para apuntar la recuperación física de alguno, uso que se encuentra registrado en la lex Aquilia ${ }^{92}$. En D. 21,1,16 (Pomp., 23 Sab.), a propósito de los vicios redhibitorios específicamente, Pomponio define qué se entiende por sanatos: "Quod ita sanatum est, ut in pristinum statum restitueretur, perinde habendum est, quasi numquam morbosum esset”.

En el contexto del Digesto, el fragmento se refiere a la existencia de vicios redhibitorios en la venta de esclavos, a propósito de cierta disposición del edicto de los ediles curules donde, muy significativamente, se denomina "mancipia" a los esclavos, como se ve en D. 21,1,1,1 (Ulp., 1 ed. aed. cur.): "Aiunt aediles: 'Qui mancipia uendunt certiores faciant emptores, quid morbi uitiiue cuique sit, quis fugitiuus erroue sit noxaue solutus non sit: eademque omnia, cum ea mancipia uenibunt, palam recte pronuntianto. quodsi mancipium aduersus ea uenisset, siue aduersus quod dictum promissumue fuerit cum ueniret, fuisset, quod eius praestari oportere dicetur: emptori omnibusque ad quos ea res pertinet iudicium dabimus, ut id mancipium redhibeatur. si quid autem post uenditionem traditionemque deterius emptoris opera familiae procuratorisue eius factum erit, siue quid ex eo post uenditionem natum adquisitum fuerit, et si quid aliud in uenditione ei accesserit, siue quid ex ea re fructus peruenerit ad emptorem, ut ea omnia restituat. item si quas accessiones ipse praestiterit, ut recipiat. item si quod mancipium capitalem fraudem admiserit, mortis consciscendae sibi causa quid fecerit, inue harenam depugnandi causa ad bestias intromissus fuerit, ea omnia in uenditione pronuntianto: ex his enim causis iudicium dabimus. hoc amplius si quis aduersus ea sciens dolo malo uendidisse dicetur, iudicium dabimus"'.

En pocas palabras, el vocablo "sanatum" es utilizado tanto en el lenguaje legislativo como en la literatura jurídica en el sentido de haberse recuperado de alguna enfermedad. Por tanto, y sobre todo teniendo presente su posible aparición en la

\footnotetext{
${ }^{91}$ Este es el sentido que da Elmore, J., Recovery, cit. (n. 90), pp. 62-64.

${ }^{92}$ Así, leemos en D. 9,2,45,1 (Paul., 10 Sab.): "Lege Aquilia agi potest et sanato uulnerato seruo".
} 
lex Aquilia, una disposición republicana distante sólo ciento cincuenta años de la Ley de las XII Tablas, debemos considerar que éste es el sentido que encierra. El sintagma "fortes sanatique" parece equiparar a los sanos (fortes) y a los que se han recuperado de alguna dolencia. Esto es especialmente interesante si consideramos el otro sintagma que se encuentra en discusión, esto es nexi mancipiique. La voz "nexi" se encuentra, aparentemente, fuera de duda, aunque no parece tan clara la inclusión de mancipiique a continuación. Sin embargo, el fragmento de 321 Festo, por mutilado que esté, si hace una expresa referencia a dicha voz y su reconstrucción parece exacta. Si Festo cuando señala: "Nex $<\mathrm{i}>$... forti sanatid ..." se encuentra justamente comentando la disposición de las XII Tablas, donde de la cita literal faltan algunos caracteres, pero luego pasa a comentar la frase "ius man<cipii nexique quod populu>s Romanus haberent", para dar sentido a tal norma del cuerpo decenviral. Aunque parte del fragmento sea una reconstrucción, debiese aceptarse la inclusión de la palabra "mancipiique" en en la primera parte. El restringir la disposición sólo a las tres palabras supervivientes de la cita literal como hacen Crawford, Burns y Riccobono es demasiado pusilánime. Por lo demás, si la cita literal se limita exclusivamente a hablar de los nexi, por qué se sacaría a colación a los mancipii entonces acto seguido. En nuestra opinión la reconstrucción de Girard sigue siendo la más atendible y la norma contempla conjuntamente a los nexi mancipiique en relación a los fortes sanatique en su antecedente. ¿Qué puede seguirse de esta idea? Posiblemente, la norma trate del caso en que quienes son nexi mancipiique hayan estado privados de razón y se hubiesen recuperado, de manera similar al empleo de la voz "sanatum" en los vicios redhibitorios. Es decir, qué pasa si una persona ha realizado un nexum y una mancipatio quedando servorum loco en relación con el adquirente cuando hubiese sido un forti sanatique. Posiblemente, en la medida que se hubiese recuperado de su dolencia mental en la época en que realizó el nexum y el mancipium, se activaría el consecuente de la misma, esto es, ita ius esto, y por tanto, el acto sería válido.

Desde nuestro punto de vista, lo importante de la norma es que, al igual que la norma contenida en 6,1, la disposición confirma la necesidad de realizar dos actos, el nexum y el mancipium, a fin que se produzca el consecuente. Así, el estado de dependencia en que los nexi caen tiene lugar sólo cuando, a consecuencia del nexum, se realiza una mancipatio por la que el deudor entra bajo el poder del adquirente. Esto nos lleva a de regreso a la vieja teoría de Huschke y Mommsen, puesto que, de acuerdo a lo que postulamos el nexum sería un negocio crediticio de carácter libral que otorga la posibilidad de evitar la manus iniectio del acreedor a través de una mancipatio que dejaría al deudor servorum loco. Así se explicarían ambas disposiciones de ley decenviral, pues Tab. 6,1 daría valor a las nuncupationes, seguramente relativas al tiempo y condiciones de servidumbre, que se realizan entre acreedor y deudor al efectuarse el nexum y el mancipium, mientras que XII Tab. 1,5 se referiría a las personas que pueden válidamente celebrarlas.

Es interesante observar que se habla de nexi mancipique para referirse a los sujetos que se encuentran servorum loco del adquirente, esto es, a las personas mismas, mientras que en 6.1 vemos que el uso de nexum mancipium sindica al acto. En ninguno de los casos que conocemos de la Ley de las XII Tablas se utiliza la 
voz como un poder específico, sea para referirse a la propiedad o a algún vínculo de carácter personal. $\mathrm{Al}$ respecto, y en contra de esta observación, una parte de la doctrina sostiene que, en el vocabulario antiguo, mancipium era equivalente a propiedad ${ }^{93}$. Sin embargo, Capogrossi ${ }^{94}$ ha realizado un estudio detallado sobre los usos de la voz "mancipium” en etapa Republicana e Imperial y concluye que la equivalencia entre propiedad y mancipium fue sólo marginal y reservada a algunos textos de carácter literario que comienzan a aparecer en la etapa imperial ${ }^{95}$, mientras que todos los textos donde se le había atribuído dicho significado de propiedad previos a tal etapa podían y debían ser interpretados en otro sentido, ya sea identificando mancipium con esclavo ${ }^{96}$, la persona in mancipio ${ }^{97}$ o con el acto de la mancipatio ${ }^{98}$. En efecto, la idea que mancipium signifique propiedad en tiempos arcaicos tiene el defecto de excluir del concepto el control que el paterfamilias tiene de los bienes nec mancipi, lo cual termina por hacer inaceptable la teoría, pues, en verdad, ni mancipium ni meum esse son idénticos a dominium ${ }^{99}$. Para los sostenedores de la teoría que identifica mancipium y dominium, las res nec mancipi serían sólo objeto de possessio ${ }^{100}$. En verdad, la equivalencia entre dominium y mancipium parece sumamente forzada. No sólo faltan los textos que permitan mantenerla, tanto jurídicos como literarios, sino que su aceptación crea graves asimetrías dentro del esquema de control de los bienes en la Etapa Arcaica. Muchísimos bienes de considerable valor económico se encontrarían, en buena medida, jurídicamente desprotegidos, como las joyas, los instrumentos de labranza, las armaduras, las espadas y las casas dentro de la ciudad, entre otros. Por lo demás, nunca se ha logrado explicar cómo fue que las acciones reales llegaron a cubrir a los bienes nec mancipi, si es que éstos no eran objeto de propiedad. Nosotros ya hemos discutido dicha posibilidad y la hemos descartado al estimar que el origen de la distinción entre res mancipi y nec mancipi se encuentran en el control gentilicio que se mantenía sobre ciertos bienes de producción. Por lo demás, si propiedad hubiese sido sinónimo de mancipium, no se entiende por qué los esclavos caen dentro de la potestas del paterfamilias y no en su mancipium. Al respecto Gayo es bastante explícito ${ }^{101} \mathrm{y}$, aunque se pudiese teorícamente alegar

${ }^{93}$ Bonfante, P., Corso. La proprietà, cit. (n. 12), II,1, p. 205; Serrao, F., Diritto privato, cit. (n. 13), I, p. 58; Kaser, M., Geteiltes Eigentum, cit. (n. 12), II, p. 80; Franciosi, Gennaro, recensión a GALlo, F., "Res mancipi” e "res nec mancipi”, en Labeo, 5 (1959) 3, p. 380; AlbANESE, B., "Cum nexum faciet mancipiumque”, cit. (n. 13), p. 94.

${ }^{94}$ Capogrossi Colognesi, L., Struttura, cit. (n. 18), I, pp. 305-348.

${ }^{95}$ Especialmente: Ovid., Ex Pont. 4,5,40; SEn., De ben. 5,19,1; Ad Lucil. 74,17; Tab Herc 65.

${ }^{96}$ Cic., Ad fam. 7,29,1.

${ }^{97}$ CiC, Brut. 1,16,4.

${ }^{98}$ Varr., De ling. Lat. 5,163; 6,74; Cic., de off. 3,67; Cic., De orat. 1,173; 1,178; Ad fam. $7,30,2$.

${ }^{99}$ DiósDI, G., Ownership, cit. (n. 13), pp. 58-60.

${ }^{100}$ Franciosi, G., recensión a Gallo, F., cit. (n. 93), pp. 380.

${ }^{101}$ Gai. 1.52 In potestate itaque sunt serui dominorum. quae quidem potestas iuris gentium est: nam apud omnes peraeque gentes animaduertere possumus dominis in seruos uitae necisque potestatem esse, et quodcumque per seruum adquiritur, id domino adquiritur. 
que Gayo es un jurista clásico y que, por tanto, lo que indica no sería aplicable a la etapa Arcaica, todavía restaría por explicar cómo fue que los hijos y los esclavos quedaron en una posición tan similar, por qué no se utiliza la voz "mancipium" para hablar de los esclavos en las XII Tablas y en qué momento posterior al cuerpo decenviral la potestas habría reemplazado al mancipium.

La voz "mancipium" con el significado de siervo es relativamente común en el lenguaje literario ${ }^{102}$. Gallo apunta que dicho sentido sería el primero y originario desde la cual nacieron las res mancipi. Sin embargo, como en su momento señaló Franciosi, esto es complejo, puesto que los orígenes de la esclavitud en Roma son discutidos ${ }^{103}$. Como ya hemos señalado en otro lugar, existe cierto consenso en que la esclavitud no fue una institución propia de la primitiva organización política que se estableció sobre el Palatino ${ }^{104}$. En efecto, parece que para la gens no era indispensable la esclavitud para obtener mano de obra subordinada que se emplease en los procesos productivos. Tal función parece estar cubierta gracias a la clientela, que encontraba entre sus primeras obligaciones el deber de opera ${ }^{105}$, esto es, de prestar su trabajo en beneficio de la gens.

Por lo demás, la posibilidad de que un ciudadano romano fuese efectivamente reducido a la esclavitud parece rara en el Derecho arcaico. En el procedimiento de la manus iniecto esto sólo era posible si, como consecuencia de la misma, éste era vendido al otro lado del Tíber ${ }^{106}$. Aunque, por otra parte, para la época de la Ley de las XII Tablas, el fur manifestus podría eventualmente devenir en esclavo por la addictio del magistrado ${ }^{107}$, creemos que tras este precepto se deja ver una supervivencia del llamado sistema histórico de noxalidad ${ }^{108}$, donde el responsable es entregado a la víctima para que ésta se vengue en su persona de las faltas por él cometidas. Aunque bien podría haber conducido en la práctica a la esclavitud, parece estar lejos de constituir la manifestación de un sistema destinado a obtener mano de obra subordinada. Se intuye en él, más bien, un elemento de carácter

${ }^{102}$ En efecto, algunos incluso creen que respecto a los esclavos es que se habría concebido el dominio ex iure quiritium por primera vez. Véase: FuentesECA, P., "Mancipium-mancipatiodominium", cit. (n. 64), p. 143.

${ }^{103}$ Franciosi, G., recensión a Gallo, F., cit. (n. 93), p. 374.

${ }^{104}$ Ibíd., p 206; De MARTINO, Francesco, Clienti e condizioni materiali in Roma arcaica, en El MISMO, Diritto economia e società nel mondo romano (Jovene, Napoli, 1997), III, pp. 82-83; De Martino, Francesco, Intorno all origine della schiavitù a Roma, en El MISMO, Diritto economia e società nel mondo romano (Jovene, Napoli, 1997), III, pp. 27-57.

${ }^{105}$ De Martino, F., Clienti, cit. (n. 104), III, pp. 82-83.

${ }^{106}$ Gellius, Noct. att. 20,1,47: "Erat autem ius interea paciscendi ac, nisi pacti forent, habebantur in uinculis dies sexaginta. Inter eos dies trinis nundinis continuis ad praetorem in comitium producebantur, quantaeque pecuniae iudicati essent, praedicabatur. Tertiis autem nundinis capite poenas dabant aut trans Tiberim peregre uenum ibant".

${ }^{107} \mathrm{Ga} .3$,189: "Poena manifesti furti ex lege xii tabularum capitalis erat. nam liber uerberatus addicebatur ei, cui furtum fecerat; utrum autem seruus efficeretur ex addictione an adiudicati loco constitueretur, ueteres quaerebant". En este sentido, SERRAO, F., Diritto privato, cit. (n. 13), I, p. 204.

${ }^{108}$ DE VISSCHER, Fernand, Le régime romain de la noxalité (Bruxelles, 1947), pp. 33; EL MISMO, Il sistema romano della nossalità, en Ivra, 11 (1960), p. 9. 
arcaizante que se mantuvo dentro del sistema penal romano exclusivamente para los supuestos más graves.

En verdad, la fuente principal de esclavos parece ser la guerra, especialmente a contar de la etapa etrusca ${ }^{109}$. En efecto, durante el gobierno de Tarquino Prisco es que las fuentes indican una primera reducción de los vencidos a la calidad de esclavos ${ }^{110}$. Por otro lado, existe una conexión entre la voz "servus" y la palabra etrusca "serve" 111 , aunque no es claro que tengan sentidos equivalentes" ${ }^{112}$.

Con el surgimiento de la ciudad estado bajo el gobierno de los reyes tarquinos es que se producen las condiciones económicas y sociales que hacen necesaria la esclavitud. La producción deja de estar íntimamente imbricada con los clanes gentilicios, toda vez que el proceso de privatización de la tierra permite una primera acumulación de capital fijo en manos individuales; por otro lado, el recién fundado Estado toma un rol central en la producción, transformándose en el gran asignador de recursos a través de una política de obras públicas fastuosa. Por último, la presencia de artesanos y comerciantes que desarrollan sus actividades económicas de manera independiente a las gentes se incrementa tanto que incluso se constituye un barrio específico para ellos denominado Barrio Etrusco ${ }^{113}$. A diferencia de las gentes, estos nuevos productores no cuentan con el trabajo subordinado de los clientes para desarrollar sus propios procesos productivos, $\mathrm{y}$ es entonces que surge la esclavitud, importada de Etruria, como modo de abastecerse de fuerza de trabajo a partir de los abundantes prisioneros que las exitosas guerras traen a Roma.

La adopción de un vocablo etrusco para designar tal tipo de servidumbre, incluso si éste no tiene un significado exactamente equivalente al de servus, es igualmente explícito en cuanto al origen de la institución de la esclavitud y la época en que esta es introducida en la sociedad romana.

En cuanto al lenguaje jurídico, la Ley de las XII Tablas se refiere a los esclavos en distintas disposiciones utilizando para ello la voz "servus". Así, en la conocida y comentada Tab. 8,3, sobre las injurias, señala: "MANU FUSTIVE SI OS FREGIT LIBERO, CCC, SI SERVO, CL POENAM SUBITO"114.

${ }^{109}$ No obstante, De Martino, F., Origine della schiavitù, cit. (n. 104), pp. 27-57, niega la veracidad de tales eventos y retrasa la vigencia efectiva de la esclavitud hasta mediados del siglo IV. Esto nos parece algo antojadizo, toda vez que la institución se encuentra claramente tratada en la Ley de las XII Tablas y existe poco margen para suponer que tal normativa se encuentre tergiversada en tantas disposiciones.

${ }^{110}$ Dion. Hal. 3,49-50; 6,19-20. Franciosi, G., Famiglia e persone, cit. (n. 17), p. 208; Serrao, F., Diritto privato, cit. (n. 13), I, p. 205.

${ }^{111}$ Benveniste, Émile, Le nom de lesclave à Rome, en Revue des Etudes Latines, 10 (1932), pp. 429 ss; De VissCher, F., "Mancipium”, cit. (n. 11), p. 246.

${ }^{112}$ Mucho menos puede afirmarse que la palabra "serve" estuviese destinada a traducir el primitivo vocablo latino "mancipium". Al respecto véanse Capogrossi ColognesI, L., Struttura, cit. (n. 18), I, p. 236; De Martino, F., Origine della schiavitù, cit. (n. 104), p. 30.

${ }^{113}$ VARRO, De ling. Lat. 5,46.

${ }^{114}$ El fragmento proviene de Paul., Coll. 2, 5, 5; Gai., 3,223; Gell., Noct. att. 20,1,32. Aparece en este lugar y con esta redacción en la mayor parte de las ediciones principales. La trasliteración del fragmento en el cuerpo principal pertenece a Bruns, C. G., Fontes, cit. (n. 36), pp. 15-40. $\mathrm{Al}$ respecto, Riccobono, S., FIRA., cit. (n. 87), pp. 21-75 da: "Iniuriarum actio aut legitima est 
Otro tanto podemos decir de Tab. 8,14: "Ex ceteris - manifestis furibus liberos verberari addicique iusserunt (Xviri) ei, cui furtum factum esset -; servos - verberibus affici et e saxo praecipitari; sed pueros impuberes praetoris arbitratu verberari voluerunt noxiamque - sarciri"115. Y de Tab. 10,6a: "Haec praeterea sunt in legibus - : 'servilis unctura tollitur omnisque circumpotatio'. - : 'Ne sumptuosa respersio, ne longae coronae, ne acerrae"116. Lo mismo cabe decir de Tab. 12,2a: "Si SERVUS FURTUM FAXIT NOXIAMVE NO[X]IT" ${ }^{117}$.

-. Legitima ex lege XII Tab.: 'qui iniuriam alteri facit, Vet XX sestertiorum poenam subito', quae lex generalis fuit : fuerunt et speciales, velut illa : 'MANU FUSTIVE SI OS FREGIT LIBERO, CCC, (SI) SerVo, CL poenam subit Sestertiorum'”. Girard, P. F. - Senn, F., Les Lois des Romains, cit. (n. 22), pp. 22-73: "Iniuriarum actio - aut legitima est aut honoraria. Legitima ex lege XII Tab.: 'qui iniuriam alteri facit, $\mathrm{V}$ et $\mathrm{XX}$ sesterciorum poenam subit $<0>$. Quae lex generalis fuit; fuerunt et speciales velut illa : - 'MANU FUSTIVE $\mathrm{S}_{\mathrm{I}}<<$ MANIFEST $>>$ Os Fregit <COLLISITUE $>$ LIBERO CCC, (SI) SERVO, Cl POENA $<<M>><$ SUNTO $>$ SUbIT $<<O>>$ SE $[$ S] TERTIORUM". Finalmente, CraWFORD, M., Ancient Roman Statutes, cit. (n. 36), pp. 555-721 y n. 40 cambia la ubicaación de la norma y la imputa a 1,14, aunque su contenido continúa siendo sustancialmente el mismo: "si os fregit libero, CCC, $<$ si $>$ seruo, CL poena $<\mathrm{e}>$ su $<\mathrm{n}>$ to".

${ }^{115}$ Aunque aquí no parece tratarse de una cita literal. El texto nuevamente corresponde a Bruns, C. G., Fontes, cit. (n. 36), pp. 15-40. Aparece sin variaciones en Riccobono, S., FIRA., cit. (n. 87), p. 53. Sin embargo, P. F. Girard, P. F. - SenN, F., Les lois des Romains, cit. (n. 22) pp. 22-73 dan el valor de cita textual a parte del texto y especialmente a la expresión "servos" que nos interesa: "—EX CETERIS — autem — MANIFESTIS FURIBUS LIBEROS VERBERARI ADDICIQUE — iusserunt (sc. Xviri) - EI CUI FURTUM FACTUM EST, SI MODO ID LUCI FECISSENT NEQUE SE TELO DEFENDISSENT ; SERVOS - item - FURTI MANIFESTI PRENSOS VERBERIBUS ADFICI ET E SAXO PRAECIPITARI; — sed pueros impuberes - praetoris - ARBITRATU VERBERARI — voluerunt — NOXIAMQUE AB HIS FACTAM Sarciri". Crawford, M., Ancient Roman Statutes, cit. (n. 36), n. 40 , por su parte, comparte la idea que "servos" sea parte de una cita literal, aunque cambia la ubicación del fragmento y atribuyéndole 1,19: "<<<si furtum manifestum est, ni pacit, uerberato >>> transque dato. $<<<s i$ seruus, uerberato deque saxo deicito. si impubes, uerberato noxiamque sarcito >>”.

${ }^{116}$ Así en Bruns, C. G., Fontes, cit. (n. 36), pp. 15-40. Por su parte Riccobono, S., FIRA., cit. (n. 87) pp. 21-75 hace bdecir: "Haec praeterea sunt in legibus: [de unctura quae]: 'servilis unctura tollitur omnisque circumpotatio'. - 'Ne sumptuosa respersio, ne longae coronae, ne acerrae praetereantur". GiraRD, P. F. - SenN, F., Les lois des Romains, cit. (n. 22), pp. 22-73 dan valor de cita textual a parte del texto y especialmente a la expresión "servilis" que nos interesa: "Haec praeterea sunt in legibus de unctura ... - - SERVILIS UNCTURA TOLLITUR OMNISQUE CIRCUMPO $<<$ R $>>$ TATIO —; quae et recte tolluntur neque tollerentur nisi fuissent - NE $<\mathrm{C}>$ SUMPTUOSA $<\mathrm{VINI}>\mathrm{RESPERSIO}$ <SIT> ...”. Finalmente CrawFord, M., Ancient Roman Statutes, cit. (n. 36), n. 40 entrega una versión bastante diferente: "<homini mortuo murratam potionem ne indato.> (prohibición de 'circumpotatio') <rogum ??? uino ne plus respargito $>$.

${ }^{117}$ Así en Bruns, C. G., Fontes, cit. (n. 36), pp. 15-40, como también en Riccobono, S., FIRA., cit. (n. 87), pp. 21-75; Girard, P. F. - SenN, F., Les Lois des Romains, cit. (n. 22), pp. 22-73 dan dos normas distintas que contendrían la voz "servos": Tab. 12,2a: "Celsus tamen differentiam facit inter legem Aquiliam et legem XII tab. Nam in lege antiqua, si servus - SCIENTO DOMINO - furtum fecit vel aliam noxam commissit — SERVI NOMINE ACTIO EST NOXALIS — nec dominus non suo nomine tenetur. at in lege Aquilia, inquit, dominus suo nomine tenetur, non serui. Utriusque legis reddit rationem, duodecim tabularum, quasi voluerit servos dominis in hac re non obtemperare. Aquiliae, quasi ignoverit servo, qui domino parvit, periturus si non fecisset. Sed si placeat, quod Iulianus scribit - 'SI SERVUS FURTUM FAX $<<S>>$ IT NOXIAMVE NO[X] $]<<\mathrm{V}>>\mathrm{IT}$, etiam ad posteriores leges pertinere, poterit dici, etiam servi nomine cum domino agi posse noxali iudicio" (Ulp., 8 ed., D., 9, 4, 2, 1); y Tab. 12,2b: “- EX MALEFICIIS FILIORUM FAMILIAS SERVORUMQUE ... NOXALES ACTIONES PRODITAE SUNT, UT LICERET PATRI DOMINOVE AUT LITIS AESTIMATIONEM SUF- 
En pocas palabras, la Ley de las XII Tablas es bastante consistente al denominar al esclavo servus, especialmente en las pocas citas literales que tenemos, mientras que no somos capaces de citar ni un solo precepto en que se denomine "mancipium" al esclavo que provenga del cuerpo decenviral. Si "mancipium” fuese el sustantivo originalmente empleado para designar al esclavo, entonces sería esperable encontrar tal palabra utilizada en este sentido a lo menos una vez dentro del texto, lo cual no sucede. Entonces, ¿`cómo explicar este uso literario relativamente común y temprano? Al respecto, intentaremos postular una hipótesis consistente con los datos con que contamos. Si nuestro conjunto de suposiciones son correctas, antes del período etrusco Roma estaba constituída por un conjunto clanes de carácter tribal que mantenían un cierto control del territorio llamados gentes. Dichas unidades tenían diferentes mecanismos para contar con trabajo subordinado a su disposición, entre los que estaría el mancipium, considerado como un acto libral en virtud del cual se adquiría a un hombre libre o a su prole a fin que prestara sus opera a favor de la gens. El uso de la mancipatio para tal menester se explica si se tiene en consideración que este acto se desarrolla para adquirir bienes de titularidad colectiva, como ya planetó Bonfante ${ }^{118}$ y nosotros defendimos recientemente. Así como se denominó res mancipi a los bienes adquiridos por mancipatio (o mancipium), llamar "mancipii" a la mano de obra libre que ha entrado bajo el control gentilicio, esto es, adquiridos a través del mancipium, parece simétrico y lógico. En este sentido, la expresión "liber in causa mancipi" no significaría "libre en condición de esclavo", sino "libre adquirido por mancipium", como ya postuló Franciosi ${ }^{119}$. Con el advenimiento de los reyes etruscos y la posterior división y privatización de los bienes de producción antiguamente controlados por las gentes, se introduce también un nuevo tipo de trabajador cosificado, el esclavo, a quien se designa con un término diferente, "servus", de origen etrusco y que lo distinguiría de los mancipii que mantienen su ciudadanía y deberes militares.

El poder ejercido sobre el servus fue la potestas. Este poder tenía la carácteristica de incluir la facultad de dar vida o retirarla, y era detentado por los padres sobre los hijos ${ }^{120}$. Así, en la fórmula de la adrogatio, una venerable antigüedad del sistema jurídico romano, figura la expresión "vitae necisque" para indicar la posición de hijo, como se ve en Cic., De domo sua 77,10: "tamen te esse interrogatum auctorne esses, ut in te P. Fonteius vitae necisque potestatem haberet, ut in filio". También en Gell., Noct. Att. 5,19,9: "Eius rogationis uerba haec sunt: 'Velitis, iubeatis, uti L. Valerius L. Titio tam iure legeque filius siet, quam si ex eo patre matreque familias

fere, aut noxae dedere...”. Finalmente Crawford, M., Ancient Roman Statutes, cit. (n. 36), n. 40: "si seruus furtum faxit noxiamue no $<\mathrm{x}>i t,<<<$ noxiae datus esto $>>>$. Las fuentes de esta disposición, que parece una cita literal, son: Ulp., 8 ed., D. 9, 4, 2, 1; FEsT., Noxia; D. 47,6,5; 50,16,283, 3; Paul. Sent. 2,31,7.

${ }^{118}$ Bonfante, P., Corso. La proprietà, cit. (n. 12), II, p. 253.

${ }^{119}$ Franciosi, G., Famiglia, cit. (n. 17), p. 52.

${ }^{120}$ En efecto, se atribuía a las leyes regias dicha facultad. Coll. 4,8,1: "Cum patri lex regia dederit in filium vitae necisque potestatem [...]”. Esta idea aparece repetida en DIONISIO DE HALICARNASO, Ant. Rom. 2,26. 
eius natus esset, utique ei uitae necisque in eum potestas siet, uti patri endo filio est. Haec ita, uti dixi, ita uos, Quirites, rogo"'.

De esta manera, cuando se adquiere la patria potestas sobre alguien, la vitae necisque potestas aparece como consustancial a ella, como su sinónimo. Quien es adrogado, por definición, queda bajo la vitae necisque potestas de su nuevo padre, como símbolo de su nueva posición de hijo. Potestas es ius vitae necisque y de ahí que se lo asimile al imperium, que es un poder absoluto, también de origen etrusco, y que implica, al menos fuera de los límites de la ciudad, el ius vitae necisque. De esta manera, el esclavo quedó bajo la potestas de su dueño justamente por el carácter absoluto que ésta ostentaba, mientras que las formas más antiguas de adquirir mano de obra a través de la mancipatio, que siguieron vigentes todavía durante largo tiempo, quedaron netamente diferenciadas. Para la época de la Ley de las XII Tablas, la diferencia entre los mancipii y los servi era nítida, tanto que lexicamente se encuentran bastante distantes. En el cuerpo decenviral se regula la situación de los primeros intentando reforzar el valor de las nuncupationes realizadas al momento de efectuarse la mancipatio, y posiblemente ese sea el sentido de las ya discutidas Tab. 1,5 y 6,1, como también la limitación de ventas del padre respecto al hijo.

Finalmente, el mancipium, como forma de adquirir personas libres entra en esclerosis, producto tanto de la prohibición del nexum contenida en la lex Poetelia Papiria, como por la entrada masiva de esclavos en la economía romana, producto de la expansión imperialista de la ciudad por Italia. En efecto, la mancipatio de los hijos de familia, única forma permitida luego de la lex Poetelia Papiria, sobrevive gracias a los creativos usos que la jurisprudencia pontifical le otorgó, más no como un medio efectivo de controlar la mano de obra. Fue en este momento en que los esclavos también pasaron a denominarse coloquialmente mancipia, por ser mano de obra sometida, una vez que los verdaderos mancipia, libres que trabajaban para otro por haber sido adquiridos por mancipatio, dejaron de estar efectivamente presentes en la realidad romana. De alguna manera, los servi son los que están in loco mancipiarum y no a la inversa, como aparece en las fuentes, puesto que los libres que prestaban opera son, probablemente, más antiguos que los esclavos.

En consecuencia, el trinomio "potestas manus mancipioque" debe pertenecer a una etapa bastante antigua del pensamiento romano, en que, por una parte, la esclavitud ya ha penetrado en la ciudad, pero el mancipium sigue siendo una forma efectiva de obtener mano de obra. Tal vez la época que más se acerque a estas características sea aquella comprendida por los primeros siglos de la República, tiempo en que las condiciones de producción y todavía son coherentes con estas instituciones. Creemos que el sintagma debió surgir tal vez en la etapa inmediatamente posterior a las XII Tablas, producto de la interpretación pontifical del conjunto de poderes del paterfamilias que, por entonces, se encontraban netamente diferenciados. 


\section{BiBLIOGRAFÍA}

Albanese, Bernardo, "Cum nexum faciet mancipiumque", ahora en Brevi studi di Diritto romano (Palermo, Palumbo, 1992).

Amunátegui Perelló, Carlos, "Loco filiae", en Carvajal, Patricio (editor), Homenaje al profesor Francisco Samper Polo (Santiago, Librotecnia, 2007).

Amunátegui Perello, Carlos, Origen de los poderes del "paterfamilias" (Madrid, Dykinson, 2009).

Amunátegui, Carlos, Casos de matrimonios "sine manu" en tiempos arcaicos, en Revista General de Derecho Romano, 10 (2008).

Arangio-Ruiz, Vincenzo, Le genti e le città (Messina, D’Angelo, 1914).

Behrends, Okko, La "mancipatio" nelle XII Tavole, en Ivra, 33 (1982).

BekKer, Ernst Immanuel, Die Aktionen des römisches Privatrechts (Berlin, F. Vahlen, 1871).

Benveniste, Émile, Le nom de Pesclave à Rome, en Revue des Etudes Latines, 10 (1932).

Betancourt, Fernando, El libro anónimo "de interdictis". Codex Vaticanus Latinus 5766 (Sevilla, Universidad de Sevilla, 1997).

Bonfante, Pietro, Corso di Diritto romano, I: Diritto di famiglia (Milano, Giuffrè, 1963).

Bonfante, Pietro, Corso di diritto romano. La proprietà (Milano, Giuffrè, 1966), II, 1 .

Bonfante, Pietro, La gens e la familia, en El MISMO, Scritti giuridici. Famiglia e successione (Torino, Unione Tipografica Editrice Torinese, 1916).

Bravo Bosch, María José, El largo camino de los "hispani” hacia la ciudadanía (Madrid, Dykinson, 2008).

BRETONE, Mario, La nozione romana di usufrutto (Napoli, Jovene, 1962).

BRUns, Carl Georg, Fontes iuris romani antiqui (Tübingen, Karl Georg, 1909).

Capogrossi Colognesi, Luigi, La struttura della proprietà e la formazione dei iura praediorum nell eta republicana (Milano, Giuffrè, 1969), I.

Casavola, Franco, "Lex Cincia". Contributo alla storia delle origini della donazione romana (Napoli, Università di Napoli, 1960).

Casinos Mora, Francisco Javier, La noción romana de "auctoritas" y la responsabilidad por "auctoritas" (Granada, 2000).

Corbett, Percy Ellwood, Roman Marriage (Oxford, Clarendon Press, 1930).

Cornil, Georges, Du “mancipium" au "dominium”, en Festschrift Paul Koschaker zum 60 Geburstag (Weimar, Böhlau, 1939), I.

Crawford, Michael, Ancient Roman Statutes (London, Institute of Classical Studies, 1996), II.

D’Ors, Álvaro, Un aviso sobre la “ley municipal", lex rescripta, en Mainake, 23 (2001).

De Martino, Francesco, Clienti e condizioni materiali in Roma arcaica, en El MISMO, Diritto economia e società nel mondo romano (Jovene, Napoli, 1997), III.

De Martino, Francesco, Intorno all origine della schiavitù a Roma, en El mismo, Diritto economia e società nel mondo romano (Jovene, Napoli, 1997), III.

De Martino, Francesco, La "gens", lo Stato e le classi in Roma antica, en Studi in onore di V. Arangio-Ruiz (Napoli, Jovene, 1953), IV.

DE VISCHER, Fernand, "Mancipium" et "res mancipi", en SDHI. 2 (1936). 
DE VISSCHER, Fernand, Le régime romain de la noxalité (Bruxelles, 1947).

De VissCher, Fernand,, Il sistema romano della nossalità, en Ivra, 11 (1960).

DiósDI, György, Ownership in Ancient and Preclassical Roman Law (Budapest, Akadémiai Kiadó, 1970).

Elmore, Jefferson, Recovery of Legal competency in the XII Tables, en Classical Philology, $20(1925) 1$.

FIORI, Roberto, “Materfamilias", en BIDR., 25-26 (1993-1994).

Franciosi, Gennaro, Famiglia e persone in Roma antica (Torino, Giappichelli, 1992).

Franciosi, Gennaro, recensión a Gallo, F., "Res mancipi" e "res nec mancipi”, en Labeo, 5 (1959) 3.

Fuenteseca Degeneffe, Margarita, La formación romana del concepto de propiedad (Madrid, Dykinson, 2004).

FuenteseCA, Pablo, “Mancipium-mancipatio-dominium”, en Labeo, 4 (1958) 2.

Gallo, Filippo, Studi sul trasferimento della proprietà in diritto romano (Torino, Giappiuchelli, 1958).

Gallo, Filippo, Studi sulla distinzione fra "res mancipi" e "res nec mancipi", en Rivista di Diritto Romano, 4 (2004).

GAUdEMET, Jean, Observations sur la “manus", en RIDA. 2 (1953).

Girard, Paul Frédéric - SenN, Félix, Les lois des Romains (Napoli, Jovene, 1977).

Hanard, Gilbert, "Manus” et mariage a lépoque archä̈que, en RIDA., 26 (1989).

HuschKe, Philipp Eduard, Ueber das Recht des "nexum" und das alte römische Schuldrecht (Leipzig, Gebauer, 1846).

Imbert, Jean, "Fides" et "nexum", en Studi in onore di Arangio-Ruiz (Napoli, Jovene, 1953), I.

Karlowa, Otto, Römische Rechtsgeschichte (Leipzig, Veit, 1885), II.

KASER, Max Der römische Eigentumsbegriff, en EL MISMO, Ausgewählte Schriften (Napoli, Jovene, 1976), II.

KaSER, Max, "Mores maiorum" und Gewohnheitsrecht, en ZSS., rom. Abt., 59 (1939).

KASER, Max, La famiglia romana arcaica, en Conferenze romanistiche (Milano, Giuffré, 1960).

Kretschmar, Paul, Das "nexum" und sein Verhältnis zum "mancipium”, en ZSS., rom. Abt., 29 (1908).

KunKel, Wolfgang, "Mater familias”, en RE. (Stuttgart, 1930), XIV,2.

LAMBerTi, Francesca, "Civitas Romana" e diritto latino fra tarda repubblica e primo principato, en Index, 39 (2010).

LeIFER, Franz, "Mancipium" und “auctoritas", en ZSS., rom. Abt., 56 (1936).

Lenel, Otto, Das “nexum”, en ZSS., rom. Abt., 23 (1902).

LeVY-Bruhl, Henri, Autour de la "mancipatio familiae", en Atti del congreso internazionale di Diritto romano e di Storia del Diritto (Verona) (Milano, Giuffrè, 1948).

LozAno Corbi, Enrique, Origen de la propiedad romana y de sus limitaciones, en Estudios de Derecho romano en memoria de Benito María Reimundo Yanes (Burgos, Universidad de Burgos, 2000), I.

MarCHI, Antonio, Storia e concetto dell obbligazione romana (Torino, 1912).

Meylan, Philippe, Origine de la formule "in potestate manu mancipioque", en Etudes offertes à Jean Macqueron (Aix-en-Provence, Faculté de Droit Aix-en-Provence, 1970). 
MitTeIs, Ludwig Ueber das “nexum”, en ZSS., rom. Abt., 22 (1901).

Mommsen, Theodor, "Nexum", en ZSS., rom. Abt., 23 (1902).

Mommsen, Theodor, Collectio librorum iuris anteiustiniani (Weidmannos, 1890, Berlín), III.

Pacchioni, Giovanni, "Nexum”. Impressioni e reminiscenzi, en Melanges Paul Frédéric Girard (reimpresión Aalen, Scientia, 1979), II.

Pacheco Caballero, Francisco, Las servidumbres prediales en el Derecho histórico español (Lleida, Pagés, 1991)-

Pflüger, Heinrich, "Nexum" und "mancipium" (Leipzig, Dunker \& Humblot).

Pugliese, Giovanni, "Res corporales" e "res incoporales", ahora en Scritti giuridici scelti (Jovene, Napoli, 1985), III.

Pugliese, Giovanni, Aperçu historique de la famille romaine, ahora en Scritti giuridici scelti (Napoli, Jovene, 1985), III.

Rosenberg, Arthur, Zur Geschichte des Latinenbundes, en Hermes, 54 (1919) 2.

Rossвach, August, Untersuchungen über die römische Ehe (Stuttgart, K. Wäden, 1853).

Sargenti, Manlio, Per una revisione della nozione dell"auctoritas" come effetto della "mancipatio", en Studi in onore di Emilio Betti (Milano, Giuffrè, 1962), IV.

Schlossmann, Siegmund, "Nexum”. Nachträgliches zum Altrömisches Schuldrecht (Leipzig, Deichert, 1904).

SerraO, Feliciano, Diritto privato economia e società nella storia di Roma (Napoli, Jovene, 2006), I-

Solazzi, Siro, Glosse a Gaio, en Studi in onore a Salvatore Riccobono (Palermo, 1936), I.

Tomulescu, Constantin, “nexum” bei Cicero, en Ivra, 17 (1966).

Treggiari, Susan, Roman Marriage (New York, Oxford University Press, 1991).

Voci, Pascuale, Esame delle tesi del Bonfante su la famiglia romana arcaica, en Studi in onore di Arangio-Ruiz (Napoli, Jovene, 1953), I.

Voigt, Moritz, Römisches Rechtgechichte (Leipzig, Liebeskind, 1892), I.

Volterra, Edoardo, Nuove ricerche sulla conventio in manum (1966), ahora en Scritti giuridici (Napoli, Jovene, 1991), III.

Watson, Allan, Rome of the XII Tables (New Jersey, Princeton University Press, 1975)-

WestBROOK, Raymond, Restrictions on Alienation in Early Law, en BiRKs, Peter (editor), New Perspectives in the Roman Law of Property. Essays for Barry Nicholas (Oxford, Clarendon, 1989). 